\title{
EVIDENCE FOR ATYPICAL CATEGORICAL SPEECH PERCEPTION IN WILLIAMS SYNDROME
}

\author{
Steve Majerus ${ }^{12}$, Martine Poncelet ${ }^{1}$, Aurélie Bérault ${ }^{1}$, Séraline Audrey ${ }^{1}$, Pascal Zesiger ${ }^{5}$, \\ Willy Serniclaes ${ }^{34} \&$ Koviljka Barisnikov ${ }^{5}$ \\ ${ }^{1}$ Université de Liège, Belgium \\ ${ }^{2}$ Fonds de la Recherche Scientifique F.R.S.- FNRS, Belgium \\ ${ }^{3}$ Université Paris Descartes, France \\ ${ }^{4}$ Centre National de la Recherche Scientifique CNRS, France \\ ${ }^{5}$ Université de Genève, Switzerland
}

To be published in: Journal of Neurolinguistics

Address for correspondence:

Steve Majerus, $\mathrm{PhD}$

Center for Cognitive and Behavioral Neuroscience

Université de Liège

Boulevard du Rectorat, B33 - 4000 Liege - Belgium

Tel : 003243664656

Email :smajerus@ulg.ac.be 


\title{
EVIDENCE FOR ATYPICAL CATEGORICAL SPEECH PERCEPTION IN WILLIAMS SYNDROME
}

\begin{abstract}
Although language processing has been described as being a relatively 'spared' cognitive function in individuals presenting with Williams syndrome (7q11.23 microdeletion; WS), some studies suggest possible alterations at the level of input speech processing. We explored categorical speech perception and non-speech auditory perception in six participants with WS, as well as in chronological age-matched or reading age-matched control groups. Categorical speech perception was explored for the b-d speech sound continuum, where speech sounds vary in spectral acoustic features, and for the d-t speech sound continuum, where speech sounds vary in temporal acoustic features. Non-speech perception was explored for sine-wave analogues of the 'b-d' continuum, which are not identified as speech stimuli. We observed a significantly increased ability in WS participants to detect subtle acoustic changes between adjacent stimuli of the b-d or the d-t continuum outside the phoneme boundary, when control participants showed absence of discrimination. This is the first study to provide evidence for an atypical sensitivity towards subtle acoustic variations during speech and non-speech auditory analysis in WS. Implications for phonological processing and reading acquisition are discussed.
\end{abstract}

179 words 


\section{INTRODUCTION}

Williams syndrome (WS; also known as Williams-Beuren syndrome or infantile hypercalcaemia) is a neurodevelopmental disorder caused by a microdeletion at the level of chromosome 7q11.23 (Korenberg et al., 2000). This relatively rare syndrome (incidence: 1:25000 life births; Greenberg, 1990) has received considerable research interest in the domain of cognitive neuroscience, since oral language processing has been described to be relatively well preserved relative to other cognitive domains such as visuo-spatial processing, numerical processing and executive control (Bellugi, Lichtenberger, Jones, Lai, \& St George, 2000; Bellugi, Wang \& Jernigan, 1994, 1998; Jarrold, Baddeley, \& Hewes, 1998; Paterson, Girelli, Butterworth, \& Karmiloff-Smith, 2006). This genetic syndrome has been put forward as providing neurodevelopmental evidence for the modularity of cognitive processing, given the very good verbal abilities relative to poor spatial abilities. However, recent data provide a more nuanced view, suggesting that language processing, although globally more preserved than spatial processing, is nevertheless atypical. For example, in the lexical and semantic domain, vocabulary knowledge is relatively well developed, with a standardized score beyond 70 for $50 \%$ of persons with WS, i.e., higher than expected based on general IQ estimates (overall intellectual functioning is typically situated in the mild to moderate mental retardation range, IQ $<70$, Mervis et al, 2000). At the same time, lexico-semantic representations may be learned and stored in an abnormal manner, as indicated by diminished lexical frequency effects, looser semantic representations, and abnormal word categorization abilities (e.g., Böhning, Starke, \& Weissenborn, 2004; Nazzi \& Karmiloff-Smith, 2002; Rossen, Klima, Bellugi, Bihrle, 1996; Temple, Almazan, \& Sherwood, 2002). The present study provides further evidence for atypical language processing in WS, by targeting the perceptual-phonological level of processing, which has been considered as being particularly well developed. 
A number of studies suggest that performance on a range of phonological processing tasks is at mental age or even chronological age appropriate levels. First, clinical descriptions of individuals with WS generally report fluent and well-articulated speech without any phonological or phonetic deformations (e.g., Bellugi et al., 2000; Reilly, Klima, \& Bellugi, 1990; Volterra, Capirci, Pezzini, Sabbadini, \& Vicari, 1996). Some individuals might even present quite remarkable abilities to acquire the phonology of foreign languages (Barisnikov, Van der Linden, \& Poncelet, 1996). Second, experimental investigations focused mainly on phonological fluency, phonological awareness and nonword repetition as estimators of phonological and metaphonological abilities. In phonological fluency tasks (e.g., the participant is asked to produce as many words as possible starting with a target phoneme), children and adults with WS generally perform at the same level as mental or even chronological age-matched controls (Barisnikov et al., 1996; Pezzini, Vicari, Volterra, Milani, \& Ossella, 1999; Volterra, Capirci, \& Caselli, 2001; Volterra et al., 1996; Volterra, Longobardi, Pezzini, Vicari, \& Antenore, 1999). However, it must be noted that phonological fluency tasks can also be performed on the basis of acoustic similarity between the target phoneme and the onset of the words. Studies investigating phonological awareness abilities, such as rhyme judgment, observed less consistently preserved performance. While Laing, Hulme, Grant, and Karmiloff-Smith (2001) observed similar performance between a group of WS participants and a control group matched for reading age on a set of measures of phonological awareness (rhyme awareness, spoonerisms) except for phoneme deletion measures. Majerus, Barisnikov, Vuillemin, Poncelet, and Van der Linden (2003) observed impaired performance on phonological awareness tasks in 4 children with WS, in comparison to chronological age-matched and vocabulary age-matched control groups.

Other studies explored performance in nonword repetition tasks, showing mental age or chronological age appropriate performance in some cases (Barisnikov et al., 1996; Böhning et 
al., 2002; Majerus et al., 2003). Interestingly, Majerus et al. (2003) varied the phonological familiarity of the nonwords to be repeated, by creating nonwords containing phoneme combinations that are frequent in the native phonology of the WS participants (high phonotactic frequency nonwords) or less frequent (low phonotactic frequency nonwords). Mental age and chronological age appropriate performance was observed for nonwords of low phonotactic frequency but not for nonwords of high phonotactic frequency. Furthermore, the 4 children with WS participating in this study presented either absent or inverted phonotactic frequency effects, suggesting an unusual organization of sublexical phonological representations in WS, relative to the standard phonotactic frequency effects observed in typically developing children and adults (Gathercole, Frankish, Pickering, \& Peaker, 1999; Majerus, Van der Linden, Mulder, Meulemans, \& Peters, 2004; Thorn \& Frankish, 2005).

These data provide a rather conflicting picture of phonological processing in WS: on the one hand, perception, identification and repetition of phonological material can lead to chronological age appropriate performance levels; in other cases, impaired or at least atypical performance patterns are observed. The impaired performance observed in some of the studies cannot be related only to poor metaphonological processes involving explicit control and awareness of phonological information, such as required during phonological awareness tasks, since the manipulation of implicit phonological variables such as phonotactic frequency also led to atypical performance patterns in individuals with WS. This raises the question of possible alterations at more fundamental levels of phonological representations in individuals with WS.

At the most basic level, phonological processing entails the perception of individual speech sounds. Currently, we do not know whether perception of individual speech sounds is preserved or atypical in WS. However, a number of studies hint to possible alterations at the level of input speech and non-speech auditory processing.Children with WS typically present 
hyperacusis, i.e. an increased sensitivity to sounds, more correctly characterized as odynacusis, i.e., a diminished pain threshold for the perception of speech and non-speech sounds (Levitin, Cole, Lincoln, \& Bellugi, 2005). This hyperacusis during early childhood is associated with increased hearing thresholds during later childhood and adulthood, leading to deafness in some cases (Marler, Elfenbein, Ryals, Urban, \& Netzloff, 2005). At the same time, children with WS are described as being attracted in an uncommon way by environmental noises and musical sounds such as the noise of an engine or a ventilator (Lenhoff, Wang, Greenbarg, \& Bellugi, 1997; Levitin \& Bellugi, 2006). Furthermore, brain imaging findings suggest abnormal perceptual processing in WS. Levitin et al. (2003), using an fMRI study design, showed that activation in superior temporal areas around the primary auditory cortex was less pronounced for music sounds as opposed to random noise in 5 participants with WS, relative to an age-matched control group. Mills, Neville and Bellugi (1996), using evoked-related potentials, also showed an abnormal positive peak at 200ms post-stimulus for words presented auditorily, emanating from temporal regions, in children with WS. Given that this peak occurred around 200ms when phonological information is accessed, and given that this peak was absent in control children and adults, these data suggest that children with WS might process phonological information in an atypical way. More generally, structural neuroanatomical findings suggest an abnormally increased or absent asymetry of left and right superior temporal regions including the primary auditory cortex (Eckert et al., 2006; Galaburda \& Bellugi, 2000; Hickok et al., 1995). All these behavioural and neuroimaging findings raise the question whether individuals with WS perceive speech sounds in the same way as do typically developing children and adults. On the one hand, the presence of hyperacusis and the neuroanatomical findings suggest that children and adults with WS might show abnormal processing of acoustic information, potentially characterized by increased sensitivity towards acoustic information; on the other hand, the progressive 
increase of hearing thresholds in older individuals with WS might lead to a diminished ability to process acoustic information. In both cases, this is likely to also affect the processing of speech sounds. In this study, we ensured that no participant showed diminished hearing thresholds, allowing us to explore the hypothesis of atypical sensitivity towards acoustic and phonological information in WS.

The aim of the present study is to explore the perception of speech sounds in children and adults with WS, by exploring more specifically categorical speech perception. Categorical speech perception is the hallmark characteristic of speech perception in typically developing children and adults and signals the existence of phonological representations for individual speech sounds via the phoneme boundary effect: increased discrimination performance is observed between two speech sounds when their acoustical characteristics are on opposite sides of the phonemic boundary and hence reflect two distinct phonological categories. Lower discrimination performance is observed between two sounds when their acoustic characteristics are at the same side relative to the phonemic boundary and hence reflect the same phoneme category despite differing in acoustic values (e.g., Liberman, Harris, Hoffman, \& Griffith, 1957; Liberman, Cooper, Shankweiler, \& Studdert-Kennedy, 1967). For example, in French, plosive consonants such as ' $d$ ' and ' $t$ ' have their categorical boundary at $0 \mathrm{~ms}$ voice onset time (VOT): consonants with a VOT (the duration between the plosive noise and the onset of vibration of vocal cords characterized by the appearance of stable formants on the spectrogram) of less than $0 \mathrm{~ms}$ will all be perceived as ' $\mathrm{d}$ ', and consonants with a VOT of more than $0 \mathrm{~ms}$ will all be perceived as ' $\mathrm{t}$ '. This implicates that normal listeners will maximally discriminate between two speech sounds having a VOT of -10 and $+10 \mathrm{~ms}$ (i.e. on opposite sides of the phonemic boundary), respectively, but not between two speech sounds having a VOT of $+20 \mathrm{~ms}$ and $+30 \mathrm{~ms}$, respectively, these speech sounds being perceived invariably as ' $t$ '. In other words, during categorical speech perception experiments, typical 
listeners do not perceive subtle variations in the acoustic signal between two speech sounds when these acoustic variations do not span the phoneme boundary (i.e, between-category discrimination).

In the present study, we assessed categorical speech perception in six participants with WS using a $\mathrm{d}-\mathrm{t}$ continuum with a VOT ranging between $-70 \mathrm{~ms}$ and $+70 \mathrm{~ms}$ originally developed by Medina, Hoonhorst, Bogliotti and Serniclaes (2010). We also explored categorical speech perception for $\mathrm{a} b$ - $\mathrm{d}$ continuum opposing two consonants being distinguished by formant transitions rather than VOTs. This continuum was originally developed by Serniclaes, Sprenger-Charolles, Carré, and Démonet (2001). This second continuum also provided the opportunity to assess non-speech perceptual processes: in a first variant of this continuum, sinewave analogues of speech sounds with varying formant transitions, corresponding to the b-d continuum, were presented; these sounds are in general perceived as whistles. When different stimulus pairs of this continuum are presented, no categorical discrimination behavior is observed when the participants are told to indicate whether the two sounds sound identical or different. However, when the participants are told that these sounds actually reflect speech sounds from a foreign language, then some mild categorical discrimination behavior is observed, i.e., the stimulus pair opposing the formant transition values corresponding to the b-d boundary in the native language of the participants will lead to higher discrimination scores than the other stimulus pairs (Serniclaes et al., 2001). Furthermore, in a third condition, the same sine-wave sounds were transformed into modulated sine-waves, resulting in an acoustic envelope closer to natural speech sounds. In this third condition, the sounds were most likely to be perceived as speech sounds and hence to elicit categorical perception behaviour. If individuals with WS have a specific difficulty at the level of extracting phonological categories for speech sounds but not of the processing of acoustic information, then they should show identical performance to controls when listening 
to the continuum in the non-speech condition (when the sounds are perceived as whistles) but not when the stimuli are perceived as speech stimuli (speech and modulated speech conditions) and this especially around the phoneme boundary. If on the other hand acoustic perceptual processing is already atypical in WS, then abnormal discrimination behaviour is expected to occur also in the non-speech condition, characterized by increased discrimination across the different stimulus pairs.

The present study used a multiple case study design, characterizing each WS participant's performance relative to a chronological age-matched control group, as well as relative to a reading age, vocabulary age and non-verbal mental age-matched control group. It is of special importance to compare the WS participants' performance to reading age-matched control groups since reading instruction (i.e. the explicit learning of the association between a written symbol and its corresponding speech sound) is known to influence performance in speech perception tasks (Morais, Bertelson, Cary \& Alegria, 1986; Serniclaes, Ventura, Morais, \& Kolinsky, 2005).

\section{METHODS}

\section{Participants}

Six cases with Williams syndrome, labeled WS1, WS2, WS3, WS4, WS5 and WS6, were selected to participate in this study. In all cases, the microdeletion at the level of 7q11.23 was confirmed using the two-color fluorescent in situ hybridization technique. The participants were all native French speakers recruited via French speaking Williams syndrome associations. All participants had to pass an audiometry test in order to exclude significant hearing impairment ( > $20 \mathrm{~dB}$ loss on both ears for frequencies between 500 and $2000 \mathrm{~Hz}$ ). Audiometry testing was performed using a MADSEN Xeta audiometer (GN Otometrics). The 
WS participants' performance was compared to that of control groups matched at the level of chronological age or reading age. There were three chronological age-matched control groups, with a mean age of 152 (CA12 group), 160 (CA13 group) and 348 months (CAAD group), and two reading age-matched control groups, with a mean reading age of 6;07 (RA6 group) and 7;05 years (RA7 group) (see Table 1). Participants WS1, WS2, WS3 and WS4 were compared to the RA6 group, since their reading age was not higher than 6 years and 8 months; their respective chronological age-matched control groups were CA13, CA12, CA12 and CAAD; participants WS5 and WS6 were compared to the RA7 group since their reading age was around 7 years and 11 months. Reading age had been established via the timed reading performance of a standardized French reading test (Lefavrais, 1967); obtained reading age takes into account both reading speed and reading accuracy. Furthermore, the WS participants were matched to their respective reading age-matched control groups in terms of non-verbal intellectual functioning, as measured by Raven's coloured progressive matrices (Raven, 1998) as well as in terms of receptive vocabulary knowledge as measured by the French adaptation of the Peabody Picture Vocabulary Test (Dunn, Thériault-Whalen, \& Dunn, 1993) (see Table 1). Informed consent had been obtained from all participants and their legal representative.

\section{$<$ INSERT TABLE 1 ABOUT HERE >}

Material

b-d continuum

This continuum was presented in three conditions: non-speech control condition, speech condition and modulated speech condition, containing each 6 auditory stimuli developed by Serniclaes et al. (2001). Within each condition, the stimuli were presented in pairs for a same-different discrimination task. For each continuum, the auditory stimuli were 
comprised of 6 sine-wave analogues (labeled A, B, C, D, E, F), corresponding to 'ba' at one end (sinewave analogue A) and to 'da' at the other end (sinewave analogue F). Second and third formant transitions for sine-wave analogue $\mathrm{C}$ corresponded to the values of the theoretical phoneme boundary for b-d as established by Serniclaes et al. The formant transitions allowing distinguishing between ' $b$ ' and ' $d$ ' were manipulated by modifying the onset of the initial frequency transition of the second and third sine-wave of each sound, and which correspond to transitions of second and third formants in natural speech (F2 and F3). The second sine-wave onset frequency varied from $700 \mathrm{~Hz}$ at the /ba/ endpoint to $2075 \mathrm{~Hz}$ at the /da/ endpoint in five equal steps of $275 \mathrm{~Hz}$, yielding a total of 6 stimuli per continuum (see Figure 1). The third sine-wave onset frequency varied from $1500 \mathrm{~Hz}$ at the /ba/ endpoint to $3875 \mathrm{~Hz}$ at the /da/ endpoint in five equal steps of $475 \mathrm{~Hz}$ (see Figure 1). The end frequencies of second and third sine-wave transition were fixed at $1300 \mathrm{~Hz}$ and $2500 \mathrm{~Hz}$ respectively (see Figure 1) The initial frequency of the first sine-wave (corresponding to F1) was $100 \mathrm{~Hz}$ and its end frequency was $750 \mathrm{~Hz}$. Total duration of each sound in each condition was $230 \mathrm{~ms}$.

Non-speech control condition: a pure sinewave synthesis method was used for creating the stimuli, using an amplitude-weighted sum of sinusoids (Equation 1). Without further specification, these stimuli are perceived as whistles.

$$
(\text { Equation } 1) \text { signal }=\mathrm{A} 1 * \sin (2 \pi \mathrm{t} / \mathrm{F} 1)+\mathrm{A} 2 * \sin (2 \pi \mathrm{t} / \mathrm{F} 2)+\mathrm{A} 3 * \sin (2 \pi \mathrm{t} / \mathrm{F} 3)
$$

Speech condition: the stimuli were exactly the same as for the non-speech control condition. However, when the participants are told that these stimuli actually reflect speech sounds, then the stimuli can be identified as /ba/ - /da/ speech sounds.

Modulated speech condition: a pitch-modulated sinewave synthesis method was used for creating the stimuli, by adding low-frequency amplitude modulation to the sinewave sounds, multiplying the signal by a negative exponential with a time constant of about $50 \mathrm{~ms}$ 
(Equation 2). This modulation is reproduced at the F0 frequency, which was constant at 100 Hz. This had the effect of giving the sounds the equivalent of a voice pitch and made them immediately appear as speech-like sounds.

$($ Equation 2$)$ signal $($ one period $)=(\mathrm{A} 1 * \sin (2 \pi \mathrm{t} / \mathrm{F} 1)+\mathrm{A} 2 * \sin (2 \pi \mathrm{t} / \mathrm{F} 2)+\mathrm{A} 3 * \sin (2 \pi \mathrm{t} / \mathrm{F} 3))^{*} \mathrm{e}^{-}$ $\mathrm{t} / 0.05$

\section{$<$ INSERT FIGURE 1 ABOUT HERE >}

d-t continuum

For the d-t continuum, all sounds were pitch-modulated sine-wave analogues, and hence appeared as speech-like sounds. They were developed by Medina, Hoonhorst, Bogliotti and Serniclaes (submitted). For the d-t continuum, there were 8 stimuli (labeled A, B, C, D, E, F, $\mathrm{G}, \mathrm{H}$ ), corresponding to /dœ/ at one end (sinewave analogue A) and to /tœ/ at the other end (sinewave analogue $\mathrm{H}$ ). The voice onset-times for sine-wave analogues $\mathrm{D}$ and $\mathrm{E}$ were close to the theoretical phoneme boundary for the d-t continuum (= VOT $0 \mathrm{~ms}$ ) as established by Serniclaes et al. (see Figure 2). Voice-onset time ranged from $-70 \mathrm{~ms}$ to $+70 \mathrm{~ms}$, with increasing steps of $20 \mathrm{~ms}$. Stable frequency of first, second and third sine-wave (formant) was $493 \mathrm{~Hz}, 1485 \mathrm{~Hz}$ and $2500 \mathrm{~Hz}$, respectively (see Figure2). Onset frequency of first, second and third sine-wave transitions was $300 \mathrm{~Hz}, 2000 \mathrm{~Hz}$ and $3100 \mathrm{~Hz}$, respectively. Total duration of the sounds ranged between $210 \mathrm{~ms}(\mathrm{~A})$ and $280 \mathrm{~ms}(\mathrm{H})$.

\section{$<$ INSERT FIGURE 2 ABOUT HERE >}

Procedure

In order to avoid speech-based analysis in the non-speech control condition, this condition was always presented first, followed by the speech and then the modulated speech conditions for the b-d continuum. Finally, the d-t continuum was presented. For each 
continuum, adjacent stimulus pairs were presented for discrimination (pairs $\mathrm{AB}, \mathrm{BC}, \mathrm{CD}, \mathrm{DE}$ and $\mathrm{EF}$ for the first three continua, pairs $\mathrm{AB}, \mathrm{BC}, \mathrm{CD}, \mathrm{DE}, \mathrm{EF}, \mathrm{FG}$, and $\mathrm{GH}$ for the d-t continuum). For each continuum, each pair was presented 8 times. There was an equal number of identical pairs (AA, BB, CC, DD, EE, FF, GG, HH). The stimulus pairs were selected in random order within each continuum and presented via high quality headphones at the rate of 1 stimulus every 2500ms. The tasks were presented using E-Prime 1.0 programming software running on a PC compatible mobile computer. Stimulus output was regulated at $80 \mathrm{~dB}$. The participants responded by pushing a button marked with a green sticker for 'same' responses, and a button marked with a red sticker for 'different' responses. Each continuum was preceded by 8 practice trials which could be repeated if necessary. For the non-speech continuum, the task instructions were the following: "We will play a game with noises coming from a very distant planet. You will hear two sounds. When the two sounds are identical, you push the green button; when they are different, you push the red button. You are ready? Here we go." For the speech continuum, the same stimuli as in the non-speech were presented but task instructions were adapted in order to present the sounds this time as possible speech sounds, and induce categorical perception response profiles: “This time, you will hear two extraterrestrians pronounce two word sounds, 'ba' and 'da'. If you hear twice the same word, 'ba-ba' or 'da-da', you push on the green button. If the words are different, such as 'ba'-'da' or 'da'-'ba', you push in the red button. You are ready?” For the modulated speech continuum, the instructions were the following: "You will now hear the same words pronounced by a different voice. As before, if you hear twice the same words, 'ba-ba' or 'da-da', you push on the green button. If the words are different, you push on the red button. You are ready?". For the d-t continuum, the task instructions were the following: “This time, you will hear two words pronounced by Robert, a robot. The words are 'deu' or 'teu'. If you hear twice the same word, 'deu-deu' or 'teu-teu', you push on the green button. 
If the words are different, such as 'deu'-'teu' or 'teu'-'deu', you push in the red button. You are ready?" In order to avoid fatigue effects, the d-t continuum was presented after a short break.

\section{Statistical analyses}

For each continuum and for each stimulus pair, we computed d' scores, integrating the number of correct responses for the corresponding different and same pairs in order to take into account response bias (Macmillan \& Creelman, 1991). For the speech, the modulated speech and the d-t continua, we expected discrimination peaks (i.e., maximum d' scores) in controls for the pair at the phonetic boundary (pair CD for the speech and modulated speech continua; pair DE for the d-t continuum) and absent or near-to-zero discrimination behaviour (i.e., d' scores close to 0 ) for all other pairs. Near-to-zero discrimination was expected for all pairs in the non-speech continuum. For each WS participant, d' scores for all pairs of each continuum were compared to his/her respective control groups, by using modified t-tests (Crawford, Garthwaite, Howell, \& Venneri, 2003). Modified t-tests give an inferential estimate of the distance between the score of a single case and the range of scores of the control group considered at the population level. If $\mathrm{p}<.05$, this signals individual performance significantly outside control range (i.e., for $\mathrm{N}_{\text {controls }}=14$, this equals to performance at least 2.25 standard deviations below or above mean performance in the control group, for a twotailed significance test). We furthermore considered performance abnormal when above the maximum score or below the minimal score of the respective control groups. 


\section{RESULTS}

Controls - non-speech, speech and modulated speech conditions (b-d continuum)

First, we explored discrimination profiles in control participants, in order to determine whether control data conformed to expected categorization behavior. For the b-d continuum, a mixed ANOVA was conducted on d' scores, with group (RA6, RA7, CA12, CA13, CAAD) as between-subject variable, and stimulus pair $(\mathrm{AB}, \mathrm{BC}, \mathrm{CD}, \mathrm{DE}, \mathrm{EF})$ and condition (nonspeech, speech, modulated speech) as within subject variables. We observed a main effect of stimulus pair, $\mathrm{F}(4,212)=55.33, \mathrm{MSE}=0.46, \mathrm{p}<.0001, \eta^{2}=.51$, and a main effect of condition, $\mathrm{F}(2,106)=3.34, \mathrm{MSE}=.47, \mathrm{p}<.05, \eta^{2}=.06$, further characterized by a condition-by-stimulus pair interaction, $\mathrm{F}(8,424)=15.53, \mathrm{MSE}=0.29, \mathrm{p}<.0001, \eta^{2}=.23$. As shown in Table 2 and Figure 3, the highest d' scores were observed for the stimulus pair corresponding to the perceptual boundary (pair $\mathrm{CD}=$ between-category discrimination) relative to all other pairs (= within-category discrimination). This effect was most pronounced in the speech condition $(\mathrm{CD}$ vs. $\mathrm{AB}, \mathrm{F}(1,53)=38.83, \mathrm{p}<.0001, \mathrm{CD}$ vs. $\mathrm{BC}, \mathrm{F}(1,53)=64.39, \mathrm{p}<.0001, \mathrm{CD}$ vs. $\mathrm{DE}$, $\mathrm{F}(1,53)=29.20, \mathrm{p}<.0001, \mathrm{CD}$ vs. $\mathrm{EF}, \mathrm{F}(1,53)=42.15, \mathrm{p}<.0001)$ and modulated speech condition $(\mathrm{CD}$ vs. $\mathrm{AB}, \mathrm{F}(1,53)=128.03, \mathrm{p}<.0001, \mathrm{CD}$ vs. $\mathrm{BC}, \mathrm{F}(1,53)=103.77, \mathrm{p}<.0001, \mathrm{CD}$ vs. DE, $\mathrm{F}(1,53)=86.80, \mathrm{p}<.0001, \mathrm{CD}$ vs. $\mathrm{EF}, \mathrm{F}(1,53)=99.04, \mathrm{p}<.0001)$, relative to the nonspeech condition $(\mathrm{CD}$ vs. $\mathrm{AB}, \mathrm{F}(1,53)=13.21$, $\mathrm{p}<.001$, $\mathrm{CD}$ vs. $\mathrm{BC}, \mathrm{F}(1,53)=1.91, \mathrm{p}=.17, \mathrm{CD}$ vs. $\mathrm{DE}, \mathrm{F}(1,53)<1$, n.s., $\mathrm{CD}$ vs. $\mathrm{EF}, \mathrm{F}(1,53)=1.64, \mathrm{p}=.21)$. No other effects were significant at $\mathrm{p}<.05$ : group effect, $\mathrm{F}(4,53)=1.37, \mathrm{MSE}=.73, \mathrm{p}=.26, \eta^{2}=.09$, condition-by-group interaction, $\mathrm{F}(8,106)<1, \mathrm{MSE}=.47, \mathrm{p}=.45, \eta^{2}=.07$, pair-by-group interaction, $\mathrm{F}(16,212)<1, \mathrm{MSE}=.46$, $\mathrm{p}=.74, \eta^{2}=.06$, and condition-by-pair-by-group interaction, $\mathrm{F}(32,424)=1.43, \mathrm{MSE}=.29, \mathrm{p}=.07$, $\eta^{2}=.10$. In sum, the five control groups showed expected perceptual categorization behavior for the speech and modulated speech conditions, and absence of discrimination for the non- 
speech condition. At the same time, it must be noted that the most pronounced discrimination patterns were observed for the modulated-speech condition.

\section{< INSERT FIGURE 3 AND TABLE 2 ABOUT HERE >}

Controls $-\mathrm{d}-\mathrm{t}$ continuum

Next, performance of the control groups was explored for the d-t continuum. Using a mixed ANOVA with group (RA6, RA7, CA12, CA13, CAAD) as between-subject variable, and stimulus pair $(\mathrm{AB}, \mathrm{BC}, \mathrm{CD}, \mathrm{DE}, \mathrm{EF}, \mathrm{FG}, \mathrm{GH})$ as within-subject variable, we observed a main effect of stimulus pair, $\mathrm{F}(6,318)=229.86, \mathrm{MSE}=.20, \mathrm{p}<.0001, \eta^{2}=.81$ and an interaction between stimulus pair and group, $\mathrm{F}(24,318)=1.71, \mathrm{MSE}=.20, \mathrm{p}<.05, \eta^{2}=.11$. The main effect of group was not significant, $\mathrm{F}(4,53)=1.95, \mathrm{MSE}=.39, \mathrm{p}=.12, \eta^{2}=.13$. As shown in Table 2 and Figure 4, the stimulus pair corresponding to the perceptual boundary (pair DE) was more often judged to be different than other pairs (DE vs. AB, F(1,53)=190.10, p<.0001, DE vs.BC, $\mathrm{F}(1,53)=480.04, \mathrm{p}<.0001$, DE vs. $C D, F(1,53)=455.87, \mathrm{p}<.0001$, DE vs. $E F, F(1,53)=575.22$, $\mathrm{p}<.0001$, DE vs. FG, F(1,53)=489.81, p<.0001, DE vs. GH, F(1,53)=629.82, $\mathrm{p}<.0001)$. As shown in Figure 4, the group by stimulus pair interaction was caused by a group difference in discrimination behavior for the two initial stimulus pairs, the older control groups showing a stronger tendency to discriminate pairs $\mathrm{AB}$ and $\mathrm{BC}$, relative to the youngest control groups: RA6: $\mathrm{F}(1,53)=4.13, \mathrm{p}=.05$, RA7: $\mathrm{F}(1,53)=3.21, \mathrm{p}=.08, \mathrm{CA12} \mathrm{F}(1,53)<1$, n.s., CA13: $\mathrm{F}(1,53)=10.67, \mathrm{p}<.01$, CAAD: $\mathrm{F}(1,53)=14.85, \mathrm{p}<.001)$. In sum, the results for the d-t continuum also show the expected phoneme boundary effect in the five control groups. 
Participants with Williams syndrome - non-speech control, speech and modulated speech conditions (b-d continuum)

The Williams syndrome participants' discrimination performance is presented in Table 3 and Figure 5 for the non-speech, the speech and the modulated speech conditions (b-d continuum). For each pair and each continuum, each WS participant's discrimination score (d' score) was compared to discrimination performance of his/her respective chronological age and reading age-matched control groups.

\section{< INSERT TABLE 3 AND FIGURE 5 ABOUT HERE >}

For the modulated speech condition, which had led to the most robust discrimination behavior in the control groups, only WS1 and WS2 showed chronological age and reading age appropriate discrimination behavior. The other four participants showed abnormal discrimination curves, relative to respective reading age and/or chronological age control groups, with diminished discrimination scores for the expected discrimination peak at pair CD (theoretical phoneme boundary; between-category pair) (WS3 and WS4) and/or significantly increased discrimination scores for the other, within-category pairs (WS3, WS4, WS5 and WS6). This increase of d' scores for within-category pairs reflected significant discrimination behavior since performance was above the threshold for chance level performance $\left(d^{\prime}>.71\right)$ in participants WS3 (pair DE), WS4 (pair AB), and WS5 (pairs DE and EF).

For the speech condition (non-modulated), which had led to slightly less pronounced discrimination profiles in the control groups, differences between the WS participants and their respective control groups were also less marked. Nevertheless, consistent with the results obtained for the modulated speech condition, WS4 showed significantly diminished discrimination for the between-category pair CD, and WS 6 showed significantly increased discrimination the within-category pair AB. WS3, although not significant, also showed 
diminished discrimination for between-category pair CD like in the modulated speech condition. Contrary to the modulated speech condition, WS1 and WS5 showed significantly diminished discrimination behavior for the between-category pair CD (and DE for WS5); however, this was due to a general bias towards responding "yes" for any stimulus pair, as reflected by scores equal to 0 or inferior to 0 for all stimulus-pairs in WS1 and WS5. This could be due to the relatively artificial character of this condition: the stimuli sounded like artificial sounds (whistles) but the participants were told that they reflected speech stimuli from a foreign language.

For the non-speech control condition, consistent with results observed in the modulated speech condition, WS4 and WS6 showed increased discrimination behavior for the pair AB. Also, like in the modulated speech condition, WS3 showed diminished discrimination behavior for pair $\mathrm{CD}$. However, the latter finding may reflect in this case response bias since the discrimination scores were equal or inferior to 0 for all stimulus pairs in the non-speech control condition. The same remark has to be raised for the significantly decreased discrimination scores for nearly all stimulus pairs in WS2 in this condition.

In sum, for the b-d continuum, abnormal discrimination behavior was observed in four out of the six participants: WS3, WS4, WS5 and WS6 presented significantly increased discrimination scores for a subset of within-category pairs while WS3 and WS4 further showed significantly reduced discrimination scores for between-category pairs.

Participants with Williams syndrome - d-t continuum

Results for the d-t continuum are presented in Table 3 and Figure 6. Consistent with previous findings, WS4 and WS6 showed atypical discrimination functions: significantly higher discrimination scores were observed for within-category pairs (pairs EF, FG and GH in 
WS4; pair BC in WS6) while discrimination scores for the between-category pair were significantly reduced, relative to chronological age and reading age-matched controls. The other WS participants showed discrimination behavior comparable to the control groups for this continuum.

\section{< INSERT FIGURE 6 ABOUT HERE >}

\section{DISCUSSION}

We explored speech perception in 6 individuals with WS, by assessing discrimination performance for the b-d continuum (variation of F2 and F3 formant transitions) and performance for the d-t continuum (variation of voice onset time). Furthermore, for the b-d continuum, the stimuli sounded like natural speech stimuli (modulated speech condition), or they sounded like artificial sounds presented as speech stimuli (speech condition) or as nonspeech stimuli (non-speech control condition). For the b-d continuum, relative to chronological age-matched or reading age-matched control groups, four out of the six WS participants (WS3, WS4, WS5, WS6) showed significantly enhanced discrimination accuracy in the non-speech, speech and/or modulated speech conditions for a subset of within-category stimulus pairs at the upper or lower ends of the continuum, stimulus pairs for which control participants generally showed absence of discrimination. Furthermore, a significantly reduced discrimination peak at the phoneme boundary for the speech or the modulated speech condition (between-category stimulus pairs) was observed in participants WS3 and WS4. For the d-t continuum, WS4 and WS6 showed a similar discrimination profile, with a significantly reduced discrimination peak at the phoneme boundary and significantly enhanced discrimination performance at the lower $(/ \mathrm{d} /)$ or upper $(/ \mathrm{t} /)$ ends of the continuum.

Before discussing the implications of the observed results for speech perception in WS, we have to rule out a number of factors not directly related to speech perception 
processes as potentially underlying the observed performance profiles in WS participants. First, the atypical discrimination results do not simply reflect random performance; the majority of data points where significantly increased discrimination behavior was observed were in line with performance above the threshold for chance level performance, as established by d' scores. Second, we have to examine whether differences in attentional capacity could explain the atypical discrimination performance during the speech perception tasks in participants with WS relative to their control groups. Differences in attentional capacity are indeed likely to exist for the WS participants and their respective chronological age-matched control groups since selective attention capacities have been shown to be below chronological age appropriate levels (e.g., Bellugi et al., 1994; Jarrold et al., 2001). At the same time, this is less likely to be the case when comparing the WS participants to their respective reading age-matched control groups which were also matched for lexical verbal abilities and non-verbal reasoning abilities, and hence also for underlying attentional requirements necessary to perform the tasks used to assess these abilities. Although diminished selective attention towards task requirements in WS participants could theoretically explain their occasionally diminished discrimination scores for within-category pairs (for example, attentional lapses causing some items to be missed, leading to diminished and close to chance-level discrimination performance), they cannot explain the significantly increased and above chance-level discrimination scores observed for between-category pairs. Furthermore, within each WS participant, the between-category pairs leading to enhanced discrimination scores were generally consistent across the different task conditions of the b-d continuum. Finally, all participants had been screened for hearing ability and any participant with significant bilateral hearing impairment (i.e. > $20 \mathrm{~dB}$ for frequencies ranging between $500 \mathrm{~Hz}$ and $2000 \mathrm{~Hz}$; ICD-10-WHO) had been discarded from inclusion in this study. 
The present results thus suggest atypical categorical speech perception in children and adults with WS. Unlike reading age-matched and chronological age-matched control groups, 4 out of 6 participants with WS showed greater discrimination accuracy for a subset of withincategory pairs at the upper or lower ends of the b-d or d-t continua, where control participants typically present the lowest discrimination accuracy in line with the categorical perception theory (Liberman et al., 1957, 1967). This suggests that individuals with WS perceive acoustic differences between stimulus pairs even if there is no phonological (phonemic) representation that matches these acoustic differences. In categorical perception experiments, typically developing children and adults perceive two phonetic variants of the same syllable as different only if the acoustic difference between the two variants spans the phonemic boundary. Controls will excel at discriminating these stimuli when the acoustic value of one stimulus of the pair is on one side of this theoretical value (e.g., VOT=-10 ms), and the acoustic value for the other stimulus on the opposite side (e.g., VOT= $+10 \mathrm{~ms}$ ). However, discrimination accuracy will be close to 0 for pairs differing to the same extent at the acoustical level, but where both stimuli are situated at the same side of the continuum (e.g., $\mathrm{VOT}=-50 \mathrm{~ms}$ and VOT=-30 $\mathrm{ms}$, or VOT $=+50 \mathrm{~ms}$ and VOT=+30 ms). Individuals with WS appear to be more sensitive to these acoustic differences in speech stimuli, suggesting that individuals with WS can use both phonological modes and acoustic modes to analyze speech stimuli, while typically developing children and adults exclusively use the phonological mode. The use of this acoustic mode during speech perception is likely to be driven by more generally enhanced abilities to process subtle acoustic differences, given that occasionally increased discrimination performance in WS participants was also observed for the nonspeech condition. At the same time, phonological modes of speech perception (as evidenced by discrimination peaks for the between-category stimulus pairs) were not perfectly stable across WS participants : although most participants showed the expected although somewhat 
diminished discrimination peaks for the between-category pair, this peak was absent for participant WS4 for both b-d and d-t continua and absent for participant WS6 for the d-t continuum; however these participants showed peaks at specific within-category pairs (pair AB for WS4 in the speech condition for the b-d continuum; pairs EF and BC for WS4 and WS6, respectively, for the d-t continuum), suggesting that the phonemic boundary could be shifted in these participants.

This kind of discrimination behavior is similar to the allophonic speech perception mode evidenced in prelinguistic children when phonemic categories are not yet established: very young infants, before some six months of age, discriminate between phonetic variants of the same phoneme where older children and adults will perceive no difference (e.g., Werker \& Tees, 1984; Kuhl, 1992, 2004). We should however note here that the individuals with WS of the present study did not present perfectly even allophonic perception profiles. Although pairs which evidenced significantly increased discrimination in WS participants were in most instances located outside the phonemic boundary, these pairs were not always straddling the allophonic boundaries. This is evident for the for the d-t continuum for which the locations of the allophonic boundaries have been evidenced in different previous studies (for a review see: Hoonhorst, Colin, Markessis, Radeau, Deltenre, \& Serniclaes , 2009). These allophonic VOT boundaries are located around -30 and $+30 \mathrm{~ms}$, between the BC and CD (straddling 40 and -20 ms VOT), and between EF and FG pairs (straddling +20 and +40 ms VOT) on the d-t continuum in the present study. Examination of Figure 6 makes it clear that increased discrimination of VOT pairs by WS children (WS4 and WS6) is not systematically located on the allophonic pairs, although sensitivity around $-40 \mathrm{~ms}$ VOT is present for one of these children (WS6). ,

The greater sensitivity towards phonologically irrelevant acoustic patterns in WS is consistent with a number of clinical descriptions of individuals with WS, being attracted in an 
atypically strong manner by environmental noises or language dialects (Lenhoff et al., 1997; Levitin \& Bellugi, 2006). At the present stade, it is premature to conclude that this sensitivity towards acoustic stimuli is associated with the hyperacusis that is characteristic of individuals with WS. However, these findings of hyperacusis, as well as the observation of functional and structural abnomalies in superior temporal areas underlying acoustic processing as well as phonetic analysis (Galaburda \& Bellugi, 2000; Levitin et al., 2005; Neville, Coffey, Holcomb, \& Tallal, 1993), are indicative of atypical acoustic processing in WS, of which atypical speech perception profiles could be one further expression.

At a more general level, increased sensitivity towards phonologically irrelevant acoustic features during categorical speech perception tasks have been associated with protracted reading development. Previous studies (Serniclaes et al., 2001, 2004; Bogliotti et al., 2008) have shown that children with dyslexia show a modest form of allophonic perception which is not simply the consequence of reduced reading proficiency. Serniclaes et al. (2004) have proposed that an increased ability to perceive subtle acoustic variations of within-category exemplars might actually hinder the acquisition of reading, since reading involves the matching of a single grapheme to a single phoneme, irrespective of the subtle acoustic variations that characterize the different instances of the same phoneme due to environmental, dialectal or emotional factors (Peterson \& Barney, 1952; Vaissière, 2005; Stevens, 2005). By extension, the increased ability of individuals with WS to perceive subtle acoustic variations in speech and non-speech stimuli could contribute to their severe difficulties in acquiring written language; the acquisition of written language is indeed severely delayed in WS as shown by the results of the present study as well as studies by other authors (Laing et al., 2001). Finally, the diminished phonemic boundaries observed in some of the WS participants in the present study as well as the atypical phonotactic frequency effects observed in earlier studies could also be explained by an increased sensitivity towards 
phonologically irrelevant acoustic variations (Majerus et al., 2003; Majerus, 2004). This increased sensitivity towards distinct acoustic features of the same phoneme could lead to the creation of not only one category for a given phoneme, but possibly multiple categories as a function of the nature and frequency of the specific acoustic variations encountered. On the one hand, this would lead to diminished, multiple or shifted phonemic boundaries, as observed in the present study. On the other hand, this would also alter phoneme co-occurrence counts. By taking as a starting point the phoneme /b/, in case of increased sensitivity towards subtle acoustic variations of the same phoneme, the phonotactic frequency of the segment /ba/ will not only depend on all co-occurrences of the phonemes /b/ and /a/, but phonotactic frequency will be weighted by the specific acoustic variations of the phoneme /b/: /ba/ where $\mathrm{VOT}$ of $/ \mathrm{b} /=-30 \mathrm{~ms}$ and $/ \mathrm{ba} /$ where VOT of $/ \mathrm{b} /=-50 \mathrm{~ms}$ might be treated as distinct segments. The usual phonotactic frequency value for the segment /ba/ in typically developing participants will be divided by the number of distinct /ba/ segments that have been retained by the phonological system of individuals with WS. This will inevitably lead to atypical phonotactic frequency effects in speech identification tasks for individuals with WS.

Finally, two of the WS participants (WS1 and WS2) showed no trend towards increased discrimination accuracy for within-category pairs, and also in participant WS3, significantly increased discrimination behavior was observed for only one within-category pair (pair DE for the b-d continuum, modulated speech condition). Interestingly, the three participants who showed the strongest and most consistent pattern of increased discrimination for between-category pairs were adult participants (WS4, WS5, WS6), while the other three participants were children aged twelve to thirteen years. Reading experience cannot explain this difference since all participants had similar reading levels. Although the present sample is too small to make any further interpretation about this observation, future studies should 
consider the possibility that evidence for atypical speech processing may be most visible in older WS participants.

To conclude, this multiple case study has demonstrated the existence of atypical speech perception profiles in four out of six individuals with WS that participated in this study. The genetic and epigenetic factors characterizing the 7q11.23 genetic microdeletion syndrome can lead to an increased sensitivity to perceive subtle acoustic variations in both speech and non-speech stimuli where typically developing children and adults perceive no such variations. This increased sensitivity towards acoustic variations of the same phonological information is likely to contribute to the severe difficulties in reading acquisition that characterize this syndrome, by hindering the unambiguous mapping between phonemes and graphemes. 


\section{ACKNOWLEDGMENTS}

We thank all the participants for their attention and time devoted to this study. 


\section{REFERENCES}

Barisnikov, K., Van der Linden, M., \& Poncelet, M. (1996). Acquisition of new words and phonological working memory in Williams syndrome: A case study. Neurocase, 2, 395-404.

Bellugi, U., Wang, P., \& Jernigan, T. L. (1994). Williams syndrome: An unusual neuropsychological profile. In S.Broman \& J. Grafman (Eds.), Atypical cognitive deficits in developmental disorders: Implications for brain functions (pp. 23-56). Hillsdale, NJ: Erlbaum.

Bellugi, U., Lichtenberger, L., Jones, W., Lai, Z., \& St George, M. (2000). The neurocognitive profile of Williams syndrome: A complex pattern of strengths and weakness. Journal of Cognitive Neuroscience, 12, 7-29.

Bogliotti, C., Serniclaes, W., Messaoud-Galusi, S., \& Sprenger-Charolles, L. (2008). Discrimination of speech sounds by dyslexic children: Comparisons with chronological age and reading level controls. Journal of Experimental Child Psychology, 101, 137-175.

Böhning, M., Starke, F., \& Weissenborn, J. (2004). Fast mapping in Williams syndrome: A single case study. In S.Bartke \& J. Siegmüller (Eds.), Williams syndrome across language (pp. 143-161). Amsterdam: John Benjamins Publishing.

Crawford, J. R., Garthwaite, P. H., Howell, D. C., \& Venneri, A. (2003). Intra-individual measures of association in neuropsychology: Inferential methods for comparing a single case with a control or normative sample. Journal of the International Neuropsychological Society, 9, 989-1000. 
Dunn, L. M., Thériault-Whalen, C. M., \& Dunn, L. M. (1993). Echelle de vocabulaire en images Peabody. Adaptation française du Peabody Picture Vocabulary Test. Toronto, Canada: Psycan.

Eckert, M. A., Galaburda, A. M., Karchemskiy, A., Liang, A., Thompson, P., Dutton, R. A. et al. (2006). Anomalous sylvian fissure morphology in Williams syndrome. NeuroImage, 33, 39-45.

Galaburda, A. M. \& Bellugi, U. (2000). Multi-level analysis of cortical neuroanatomy in Williams syndrome. Journal of Cognitive Neuroscience, 12, 74-88.

Gathercole, S. E., Frankish, C. R., Pickering, S. J., \& Peaker, S. (1999). Phonotactic influences on short-term memory. Journal of Experimental Psychology: Human Learning and Memory, 25, 84-95.

Grant, J., Karmiloff-Smith, A., Gathercole, S. E., Paterson, S., Howlin, P., Davies, M. et al. (1997). Phonological short-term memory and its relationship to language in Williams syndrome. Cognitive Neuropsychiatry, 2, 81-99.

Grant, J., Karmiloff-Smith, A., Berthoud, I., \& Christophe, A. (1996). Is the language of people with Williams syndrome mere mimicry? Phonological short-term memory in a foreign language. Cahiers de Psychologie Cognitive/Current Psychology of Cognition, $15,615-628$.

Greenberg, F. (1990). Williams syndrome professional symposium. American Journal of Medical Genetics, 6, 85-88. 
Hickok, G., Neville, H. J., Mills, D. L., Jones, W., Rossen, M., \& Bellugi, U. (1995).

Electrophysiological and quantitative MR analysis of the cortical auditory system in Williams syndrome. Cognitive Neurosciene Society Abstracts, 2, 66.

Hoonhorst, I., Colin, C., Radeau, M., Deltenre, P., \& Serniclaes, W. (2009). French native speakers in the making: from language-general to language-specific voicing boundaries. Journal of Experimental Child Psychology, 104, 353-366.

Jarrold, C., Baddeley, A. D., \& Hewes, A. K. (1998). Verbal and nonverbal abilities in the Williams syndrome phenotype: Evidence for diverging developmental trajectories. Journal of Child Psychology and Psychiatry and Allied Disciplines, 39, 511-523.

Korenberg, J. R., Chen, X. N., Hirota, H., Lai, Z., Bellugi, U., Burian, D. et al. (2000). Genome structure and cognitive map of Williams syndrome. Journal of Cognitive Neuroscience, 12, 89-107.

Kuhl, P. (2004). Early language acquisition: cracking the speech code. Nature Reviews Neuroscience, 5, 831-843.

Kuhl, P. K. (1992). Psychoacoustics and speech perception: Internal standards, perceptual anchors, and prototypes. In L.A.Werner \& E. W. Rubel (Eds.), Developmental psychacoustics (pp. 293-332). Washington: American Psychological Association.

Laing, E., Hulme, C., Grant, J., \& Karmiloff-Smith, A. (2001). Learning to read in Williams syndrome: Looking beneath the surface of atypical reading development. Journal of Child Psychology and Psychiatry, 42, 729-739.

Lefavrais, P. (1967). Test de l'Alouette - 2nd Edition. Paris: Editions du Centre de Psychologie Appliquée. 
Lenhoff, H. M., Wang, P. P., Greenberg, F., \& Bellugi, U. (1997). Williams syndrome and the brain. Scientific American, 277, 68-73.

Levitin, D. J., Menon, V., Schmitt, J. E., Eliez, S., White, C. D., Glover, G. H. et al. (2003). Neural Correlates of Auditory Perception in Williams Syndrome: An fMRI Study. NeuroImage, 18, 74-82.

Levitin, D. J., Cole, K., Lincoln, A., \& Bellugi, U. (2005). Aversion, awareness, and attraction: investigating claims of hyperacusis in the Williams syndrome phenotype. Journal of Child Psychology and Psychiatry, 46, 514-524.

Levitin, D. J. \& Bellugi, U. (2006). Rhythm, timbre and hyperacusis in Williams-Beuren syndrome. In C.Morris, H. M. Lenhoff, \& P. Wang (Eds.), Williams-Beuren Syndrome: Research and Clinical Perspectives (pp. 343-358). Baltimore: Johns Hopkins University Press.

Liberman, A. M., Harris, K. S., Hoffman, H., \& Griffith, B. (1957). The discrimination of speech sounds within and across phoneme boundaries. Journal of Experimental Psychology, 54, 358-368.

Liberman, A. M., Cooper, F. S., Shankweiler, D., \& Studdert-Kennedy, M. (1967). Perception of the speech code. Psychological Review, 47, 431-461.

Majerus, S., Barisnikov, K., Vuillemin, I., Poncelet, M., \& Van der Linden, M. (2003). An investigation of verbal short-term memory and phonological processing in four children with Williams syndrome. Neurocase, 9, 390-401.

Majerus, S., Van der Linden, M., Mulder, L., Meulemans, T., \& Peters, F. (2004). Verbal short-term memory reflects the sublexical organization of the phonological language 
network: Evidence from an incidental phonotactic learning paradigm. Journal of Memory and Language, 51, 297-306.

Marler, J. A., Elfenbein, J. L., Ryals, B. M., Urban, Z., \& Netzloff, M. L. (2005). Sensorineural hearing loss in children and adults with Williams syndrome. American Journal of Medical Genetics, 138, 318-327.

Medina, M., Hoonhorst, I., Bogliotti, C., \& Serniclaes, W. (2010). Development of voicing perception in French: Comparing adults, adolescents and children. submitted.

Mervis, C. B., Robinson, B. F., Bertrand, J., Morris, C. A., Klein-Tasman, B. P., \& Armstrong, S. C. (2000). The Williams syndrome cognitive profile. Brain and Cognition, 44, 604-628.

Mills, D. L., Neville, H., \& Bellugi, U. (1996). Cerebral organization for spared cognitive functions in adults with Williams syndrome. Presented at the Williams Syndrome Association Professional Conference, King of Prussia, PA..

Morais, J., Bertelson, P., Cary, L., \& Alegria, J. (1986). Literacy training and speech analysis. Cognition, 45-64.

Nazzi, T. \& Karmiloff-Smith, A. (2002). Early categorization abilities in young children with Williams syndrome. NeuroReport, 13, 1259-1262.

Neville, H. J., Coffey, S., Holcomb, P. J., \& Tallal, P. (1993). The neurobiology of sensory and language processing in language-impaired children. Journal of Cognitive Neuroscience, 5, 235-253. 
Paterson, S., Girelli, L., Butterworth, B., \& Karmiloff-Smith, A. (2006). Are numerical impairments syndrome specific? Evidence from Williams syndrome and Down's syndrome. Journal of Child Psychology and Psychiatry, 47, 190-204.

Peterson, L. R. \& Peterson, M. J. (1959). Short-term retention of individual verbal items. Journal of Verbal Learning and Verbal Behavior, 10, 346-354.

Pezzini, G., Vicari, S., Volterra, V., Milani, L., \& Ossella, M. T. (1999). Children with Williams Syndrome: Is there a single neuropsychological profile? Developmental Neuropsychology, 15, 141-155.

Raven, J. C., Court, J. H., \& Raven, J. (1998). Progressive Matrices couleur. Oxford, UK: Oxford Psychologists Press.

Reilly, J., Klima, E. S., \& Bellugi, U. (1990). Once more with feeling: Affect and language in atypical populations. Development and Psychopathology, 2, 367-391.

Rossen, M., Klima, E. S., Bellugi, U., Bihrle, A., \& Jones, W. (1996). Interaction between language and cognition: Evidence from Williams syndrome. In J.H.Beitchman, N. Cohen, M. Konstantareas, \& R. Tannock (Eds.), Language, learning, and behavior disorders: Developmental, biological, and clinical perspectives (pp. 367-392). New York: Cambridge University Press.

Serniclaes, W., Sprenger-Charolles, L., Carré, R., \& Démonet, J. F. (2001). Perceptual discrimination of speech sounds in developmental dyslexia. Journal of Speech, Language and Hearing Research, 44, 384-399.

Serniclaes, W., Ventura, P., Morais, J., \& Kolinsky, R. (2005). Categorical perception of speech in illiterate adults. Cognition, B35-B44. 
Stevens, K. N. (2005). Features in Speech Perception and Lexical Access. In D.Pisoni \& E. Remez (Eds.), The Handbook of Speech Perception (pp. 125-155). Oxford: Blackwell.

Temple, C. M., Almazan, M., \& Sherwood, S. (2002). Lexical skills in Williams syndrome: A cognitive neuropsychological analysis. Journal of Neurolinguistics, 15, 463-495.

Thorn, A. S. \& Frankish, C. R. (2005). Long-Term Knowledge Effects on Serial Recall of Nonwords Are Not Exclusively Lexical. Journal of Experimental Psychology: Learning, Memory, and Cognition, 31, 729-735.

Vaissière, J. (2005). Perception of intonation. In D.Pisoni \& E. Remez (Eds.), The Handbook of Speech Perception (pp. 236-263). Oxford: Blackwell.

Volterra, V., Longobardi, E., Pezzini, G., Vicari, S., \& Antenore, C. (1999). Visuo-spatial and linguistic abilities in a twin with Williams syndrome. Journal of Intellectual Disability Research, 43, 294-305.

Volterra, V., Capirci, O., \& Caselli, M. C. (2001). What atypical populations can reveal about language development: The contrast between deafness and Williams syndrome. Language and Cognitive Processes, 16, 219-239.

Volterra, V., Capirci, O., Pezzini, G., Sabbadini, L., \& Vicari, S. (1996). Linguistic abilities in Italian children with Williams syndrome. Cortex, 32, 663-677.

Werker, J. \& Tees, R. (1984). Cross-language speech perception evidence for perceptual reorganization during the first year of life. Infant Behavior and Development, 49-63. 
Table 1. Demographic data and matching variables for the participants with Williams

syndrome and control groups

\begin{tabular}{|c|c|c|c|c|c|c|}
\hline & Age & Gender & $\begin{array}{l}\text { Raven } \\
\text { scores }\end{array}$ & $\begin{array}{l}\text { EVIP } \\
\text { scores }\end{array}$ & $\begin{array}{c}\text { Reading } \\
\text { performance }{ }^{1}\end{array}$ & Reading age $^{2}$ \\
\hline \multicolumn{7}{|l|}{ Controls } \\
\hline CA12 $(\mathrm{N}=10)$ & $\begin{array}{c}152 \\
(1.65)\end{array}$ & $5 f$ & $\begin{array}{l}32.90 \\
(1.29)\end{array}$ & $\begin{array}{l}141.70 \\
(12.67)\end{array}$ & $\begin{array}{c}223 \\
(6.67)\end{array}$ & $\begin{array}{c}11 ; 8 \\
(10 ; 11-12 ; 2)\end{array}$ \\
\hline CA13 $(\mathrm{N}=10)$ & $\begin{array}{c}160 \\
(6.99)\end{array}$ & $7 \mathrm{f}$ & $\begin{array}{l}31.40 \\
(2.59)\end{array}$ & $\begin{array}{l}138.10 \\
(11.32)\end{array}$ & $\begin{array}{c}209 \\
(40.59)\end{array}$ & $\begin{array}{c}11 ; 2 \\
(8 ; 3-14 ; 3)\end{array}$ \\
\hline CAAD $(\mathrm{N}=10)$ & $\begin{array}{c}348 \\
(70.86)\end{array}$ & $7 \mathrm{f}$ & $\begin{array}{l}34.70 \\
(1.06)\end{array}$ & $\begin{array}{l}160.00 \\
(6.11)\end{array}$ & $\begin{array}{c}150 \\
(44.93)\end{array}$ & $\begin{array}{c}12 ; 2 \\
(10 ; 7-14 ; 3)\end{array}$ \\
\hline RA6 $(\mathrm{N}=14)$ & $\begin{array}{c}79 \\
(4.64)\end{array}$ & $6 \mathrm{f}$ & $\begin{array}{l}23.14 \\
(4.22)\end{array}$ & $\begin{array}{l}92.79 \\
(13.70)\end{array}$ & $\begin{array}{c}56.79 \\
(26.02)\end{array}$ & $\begin{array}{c}6 ; 7 \\
(6 ; 6-7 ; 1)\end{array}$ \\
\hline RA7 (N=14) & $\begin{array}{l}88.07 \\
(3.15)\end{array}$ & $7 \mathrm{f}$ & $\begin{array}{l}27.21 \\
(3.31)\end{array}$ & $\begin{array}{l}105.00 \\
(8.98)\end{array}$ & $\begin{array}{l}111.36 \\
(15.69)\end{array}$ & $\begin{array}{c}7 ; 5 \\
(7 ; 1-7 ; 10)\end{array}$ \\
\hline Williams syndrom & & & & & & \\
\hline WS1 & 175 & $\mathrm{~m}$ & 20 & 93 & 59 & $6 ; 8$ \\
\hline WS2 & 145 & $\mathrm{f}$ & 20 & 98 & 24 & $6 ; 6$ \\
\hline WS3 & 152 & $\mathrm{f}$ & 29 & 141 & 24 & $6 ; 6$ \\
\hline WS4 & 242 & $\mathrm{f}$ & 15 & 110 & 30 & $6 ; 6$ \\
\hline WS5 & 340 & $\mathrm{~m}$ & 30 & 124 & 116 & $7 ; 6$ \\
\hline WS6 & 259 & $\mathrm{f}$ & 22 & 119 & 144 & $7 ; 11$ \\
\hline
\end{tabular}


Legends: CA12, CA13, CAAD: chronological age control groups for 12-year-old, 13-year-old and adult WS participants respectively; RA6 and RA7: reading age matched control groups with a mean reading age of 6 and 7 years, respectively.

${ }^{1}$ Reading performance expressed as the total number of words read during 3 minutes (for RA6 and RA7 groups and all participants with Williams syndrome) or the number of seconds taken to read the text (for AC12, AC13 and CAAD groups).

${ }^{2}$ Reading age expressed in years and months; note that the highest possible reading age is 14 years for this test. 
Table 2. Discrimination scores (means and range) for control groups for each pair in each condition.

\begin{tabular}{|c|c|c|c|c|c|}
\hline & CA12 & CA13 & CAAD & RA6 & RA7 \\
\hline \multicolumn{6}{|c|}{ b-d continuum - non-speech control } \\
\hline \multirow[t]{2}{*}{$\mathrm{AB}$} & -.35 & -.03 & .07 & .11 & .02 \\
\hline & $(-1.85-.83)$ & $(-.38-.38)$ & $(-.86-.38)$ & $(-.38-.83)$ & $(-1.21-.47)$ \\
\hline \multirow[t]{2}{*}{$\mathrm{BC}$} & .05 & .20 & .42 & .10 & .21 \\
\hline & $(-.38-.86)$ & $(-.35-.85)$ & $(-.00-1.53)$ & $(-.47-1.46)$ & $(-.47-1.21)$ \\
\hline \multirow[t]{2}{*}{$\mathrm{CD}$} & .17 & .29 & .49 & .25 & .48 \\
\hline & $(-.86-.83)$ & $(-.67-1.85)$ & $(-.00-1.85)$ & $(-.38-.99)$ & $(-1.21-1.85)$ \\
\hline \multirow[t]{2}{*}{$\mathrm{DE}$} & .12 & .69 & .38 & .20 & .09 \\
\hline & $(-.83-.85)$ & $(-.47-2.68)$ & $(-.00-1.85)$ & $(-.38-.85)$ & $(-.85-1.34)$ \\
\hline \multirow[t]{2}{*}{$\mathrm{EF}$} & .10 & .54 & .27 & .03 & .12 \\
\hline & $(-.35-.85)$ & $(-.00-1.21)$ & $(-00-1.46)$ & $(-1.53-1.85)$ & $(-.63-.83)$ \\
\hline
\end{tabular}

b-d continuum - speech

$\begin{array}{cccccc}\mathrm{AB} & .35 & -.15 & -.21 & -.14 & .07 \\ \mathrm{BC} & (-.00-1.46) & (-.85-.85) & (-.85-.38) & (-1.82-1.15) & (-.83-1.21) \\ & -.05 & .05 & .21 & -.06 & -.04 \\ \mathrm{CD} & (-.47-.38) & (-.38-.47) & (-.35-1.15) & (-1.15-1.34) & (-2.20-.47) \\ & 1.14 & 1.50 & .72 & .86 & .81 \\ \mathrm{DE} & (-.00-3.47) & (-.00-3.07) & (-.35-2.20) & (-.00-3.06) & (-1.34-2.68) \\ & .22 & .19 & .52 & .19 & .08 \\ \mathrm{EF} & (-.38-.85) & (-.85-2.68) & (-.32-1.85) & (-.38-1.21) & (-.47-1.53) \\ & .13 & .04 & .17 & .02 & .07 \\ & (-1.15-2.20) & (-1.46-2.21) & (-.35-.83) & (-.67-1.82) & (-1.15-.85)\end{array}$

b-d continuum - modulated speech 


$\begin{array}{cccccc}\mathrm{AB} & -.10 & -.04 & -.04 & -.09 & .06 \\ \mathrm{BC} & (-.48-.38) & (-1.21-.83) & (-.38-.38) & (-.83-.38) & (-.38-.85) \\ & .18 & .13 & -.17 & .24 & -.11 \\ \mathrm{CD} & (-.48-.99) & (-.35-.85) & (-1.15-.47) & (-.85-1.21) & (-1.21-.85) \\ & 1.84 & 1.83 & 1.66 & 1.13 & .96 \\ \mathrm{DE} & (.99-2.68) & (-.00-2.68) & (-.00-3.07) & (-.00-3.06) & (-.35-3.06) \\ & .19 & .35 & .11 & .21 & .07 \\ \mathrm{EF} & (-38--.83) & (-.67-1.85) & (-.38-.99) & (-1.15-2.68) & (-.38-1.21) \\ & .07 & .03 & .16 & -.01 & .08 \\ & (-.86-1.21) & (-.83-.67) & (-.38-.67) & (-.83-.83) & (-.47-.85)\end{array}$

d-t continuum

\begin{tabular}{|c|c|c|c|c|c|}
\hline \multirow[t]{2}{*}{$\mathrm{AB}$} & .26 & .84 & .92 & .30 & .27 \\
\hline & $(-.00-1.15)$ & $(-.00-1.82)$ & $(-.00-2.68)$ & $(-.38-1.82)$ & $(-.38-.85)$ \\
\hline \multirow[t]{2}{*}{$\mathrm{BC}$} & .12 & .13 & .08 & .03 & -.06 \\
\hline & $(-.00-.47)$ & $(-.85-.85)$ & $(-.00-.38)$ & $(-.38-.83)$ & $(-1.21-.85)$ \\
\hline \multirow[t]{2}{*}{$\mathrm{CD}$} & .19 & .18 & -.05 & .11 & -.05 \\
\hline & $(-.00-1.47)$ & $(-1.21-1.46)$ & $(-.85-.38)$ & $(-.38-1.21)$ & $(-.85-.38)$ \\
\hline \multirow[t]{2}{*}{$D E$} & 2.69 & 2.65 & 2.74 & 2.17 & 2.06 \\
\hline & $(-.31-3.07)$ & $(1.35-3.06)$ & $(1.82-3.06)$ & $(-.38-3.06)$ & $(.31-3.06)$ \\
\hline \multirow[t]{2}{*}{$\mathrm{EF}$} & -.10 & -.04 & .17 & -.03 & -.06 \\
\hline & $(-.64-.00)$ & $(-.38-.38)$ & $(-.85-1.21)$ & $(-.47-.47)$ & $(-.85-.38)$ \\
\hline \multirow[t]{2}{*}{$\mathrm{FG}$} & -.12 & -.00 & -.00 & -.03 & .08 \\
\hline & $(-.86-.00)$ & $(-.38-.38)$ & $(-.00-.00)$ & $(-.38-.38)$ & $(-.38-.38)$ \\
\hline \multirow[t]{2}{*}{$\mathrm{GH}$} & -.15 & -.00 & -.00 & -.08 & .11 \\
\hline & $(-1.15-.00)$ & $(-.00-.00)$ & $(-.00-.00)$ & $(-.83-.47)$ & $(-.00-.38)$ \\
\hline
\end{tabular}


The between-category stimulus pair (theoretical phoneme boundary) is printed in italic. 
Table 3. Discrimination scores for each WS participant for each pair in each condition.

\begin{tabular}{ccccccc}
\hline \multicolumn{2}{c}{ WS1 } & WS2 & WS3 & WS4 & WS5 & WS6 \\
\hline \multicolumn{2}{l}{ b-d continuum - non-speech control } & & & & \\
AB & -.00 & $\mathbf{- . 8 3} * *$ & .00 &. $\mathbf{6 7} *$ & -.00 & $\mathbf{. 6 7} * *$ \\
BC & -.00 & $\mathbf{- . 8 3} * *$ & -.38 & .36 & -.00 & .00 \\
CD & .38 & $\mathbf{- . 8 3} * *$ & $\mathbf{- . 4 8} * *$ & .36 & 0.99 & -.00 \\
DE & -.00 & $\mathbf{- . 4 8} * *$ & -.00 & 36 & 1.15 & .38 \\
EF & .38 & .00 & .00 & .83 & .86 & -.00
\end{tabular}

b-d continuum - speech

$\begin{array}{lcccccc}\mathrm{AB} & .00 & .38 & .00 & -.38 & -.00 & \mathbf{. 6 7} * \\ \mathrm{BC} & .00 & -.38 & .00 & .48 & -.00 & .36 \\ \mathrm{CD} & \mathbf{- . 4 8 * *} & .00 & -.00 & \mathbf{- . 3 6} * * & \mathbf{- . 4 8} * & 1.35 \\ \mathrm{DE} & \mathbf{- . 8 6} * * & .32 & -.00 & -.32 & -.36 * & -.00 \\ \mathrm{EF} & -.38 & .32 & .32 & .67 & -.00 & -.00\end{array}$

b-d continuum - modulated speech

$\begin{array}{lcccccc}\mathrm{AB} & .00 & -.38 & -.48 & \mathbf{. 8 6} * * & -.00 & \mathbf{. 4 8} * \\ \mathrm{BC} & .00 & -.00 & -.48 & \mathbf{. 4 8} * & -.00 & .00 \\ \mathrm{CD} & 1.35 & .38 & \mathbf{. 4 8} * & \mathbf{- . 3 8} * * & 1.53 & 1.15 \\ \mathrm{DE} & .00 & .38 & \mathbf{. 8 6} * & -.00 & \mathbf{1 . 8 5} * * & .38 \\ \mathrm{EF} & .38 & .38 & .38 & -.38 & \mathbf{1 . 2 2} * * & .38\end{array}$

d-t continuum

$\begin{array}{lcccccc}\mathrm{AB} & .38 & -.00 & -0.00 & \mathbf{- . 4 8} * * & -.00 & .48 \\ \mathrm{BC} & -.00 & -.00 & -0.00 & -.00 & -.00 & \mathbf{1 . 2 2} * * \\ \mathrm{CD} & -.00 & -.00 & -0.00 & \mathbf{. 3 8} * & -.00 & -.36\end{array}$




$\begin{array}{lcccccc}D E & 3.07 & 2.21 & 2.30 & \mathbf{. 0 0} * * & 3.07 & \mathbf{- . 0 0} * * \\ \text { EF } & -.00 & -.00 & -.38 & \mathbf{1 . 1 5} * * & -.00 & .00 \\ \text { FG } & -.00 & -.00 & -.00 & \mathbf{. 3 6} * & -.00 & \mathbf{- . 4 8} * * \\ \text { GH } & -.00 & -.00 & -.06 & \mathbf{. 8 6} * * & -.00 & .00\end{array}$

Abnormal scores, relative to respective chronological age control group performance are printed in bold and indicated by *. Abnormal scores relative to respective reading age control group performance are printed in bold and indicated by **. For the definition of abnormal scores, see Methods section. 


\section{FIGURE LEGENDS}

Figure 1. F1 and F2 formant values for the b-d continuum. A indicates stimulus A and F indicates stimulus $\mathrm{F}$ of the continuum (see methods).

Figure 2. Spectrograms for stimuli A to $\mathrm{H}$ of the d-t continuum.

Figure 3. Discrimination profiles for the control groups for the b-d continuum. Bars indicate standard errors.

Figure 4. Discrimination profiles for the control groups for the d-t continuum. Bars indicate standard errors.

Figure 5. Discrimination profiles for the Williams syndrome participants for the b-d continuum. Triangles indicate significantly higher (upwards pointing triangle) or lower (downwards pointing triangle) discrimination scores in Williams syndrome participants relative to chronological age-matched (empty triangles) or reading age-matched (full triangles) control groups (see also Methods section).

Figure 6. Discrimination profiles for the Williams syndrome participants for the d-t continuum. Triangles indicate significantly higher (upwards pointing triangle) or lower (downwards pointing triangle) discrimination scores in Williams syndrome participants relative to chronological age-matched (empty triangles) or reading age-matched (full triangles) control groups (see also Methods section). 
Figure 1

Formant 2

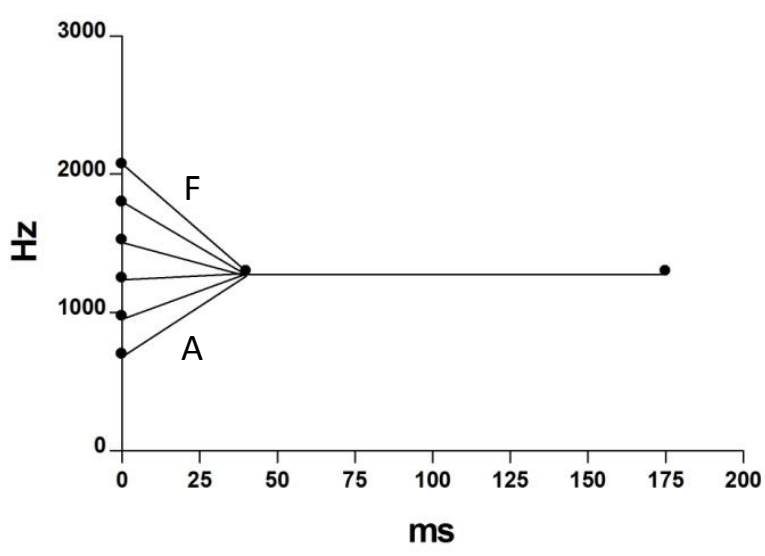

Formant 3

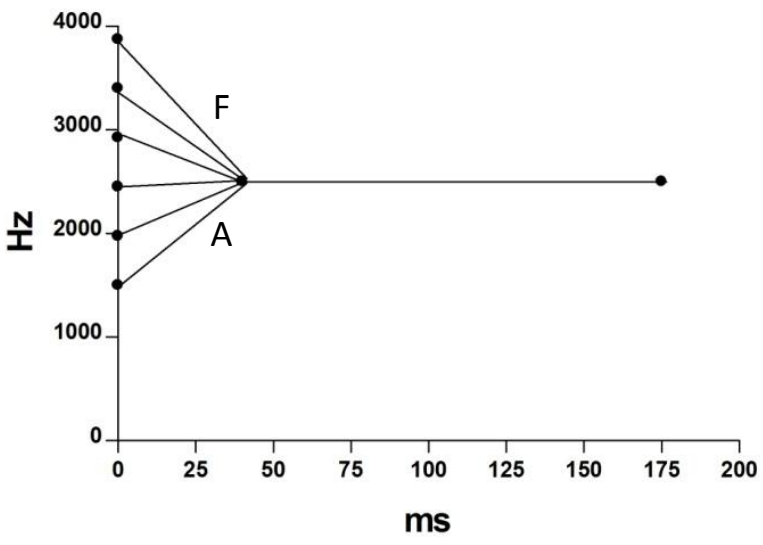


Figure 2

A

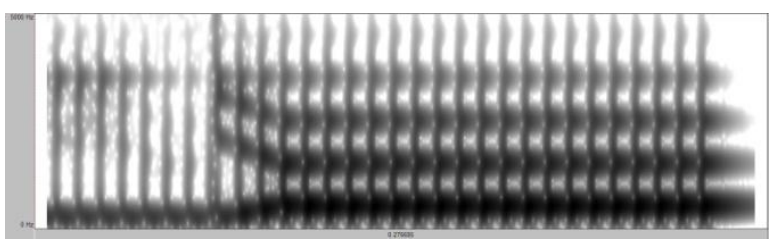

C

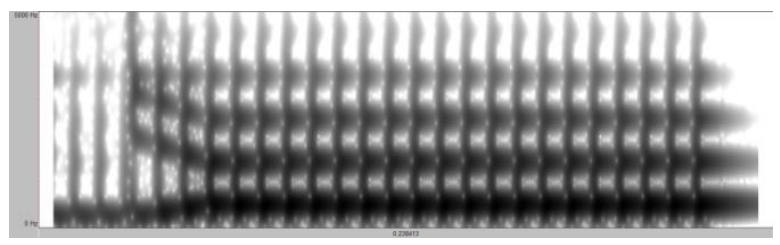

E

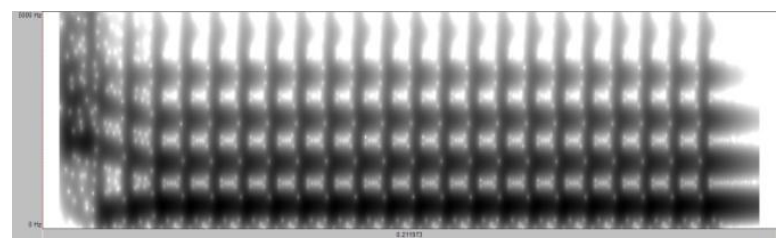

G

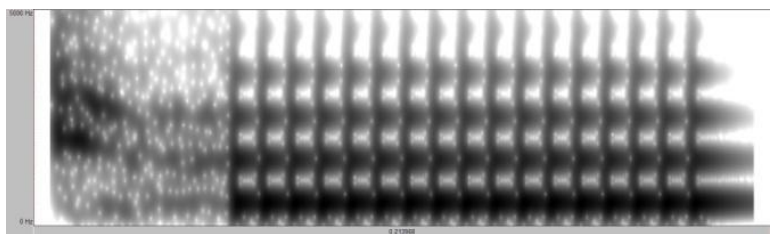

B

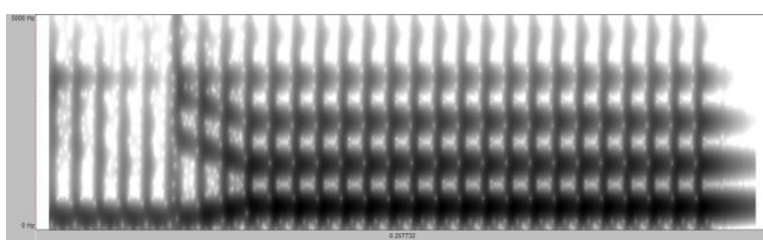

D

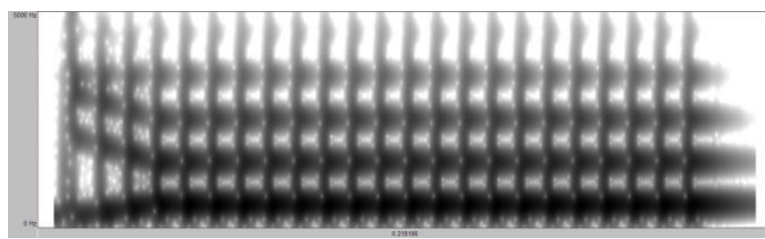

F

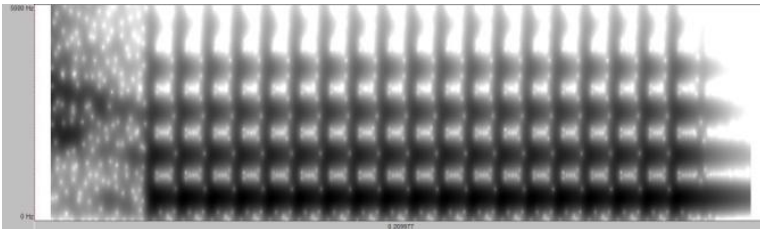

$\mathrm{H}$

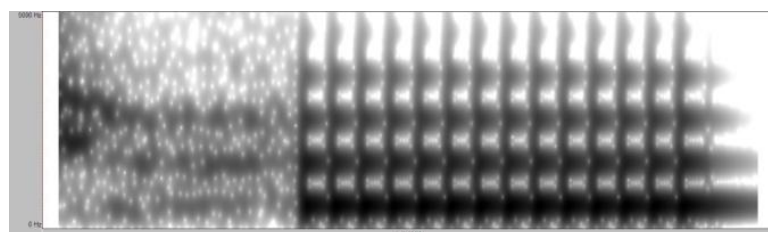


Figure 3

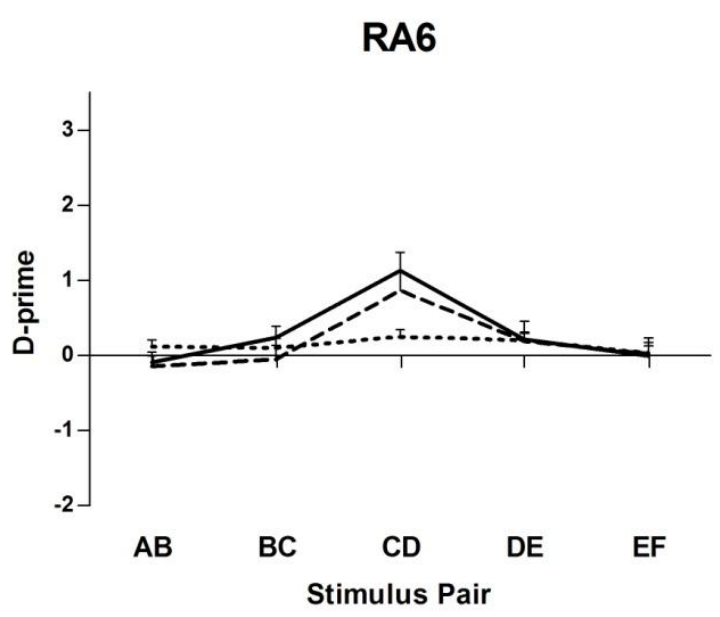

CA12

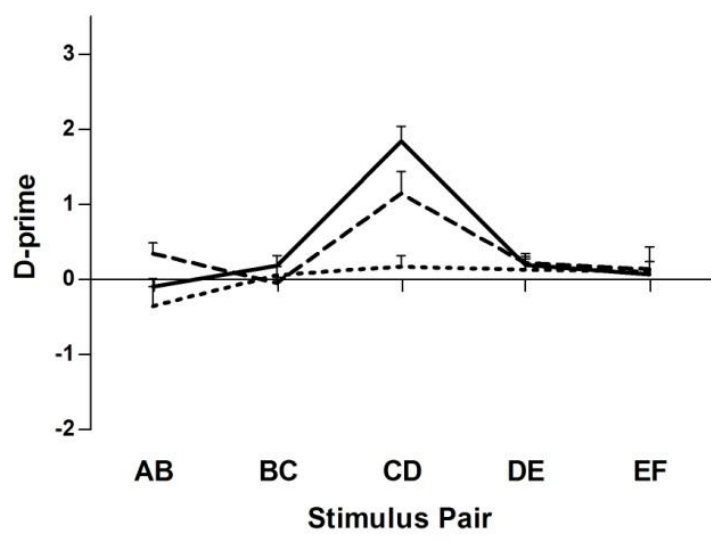

CAAD

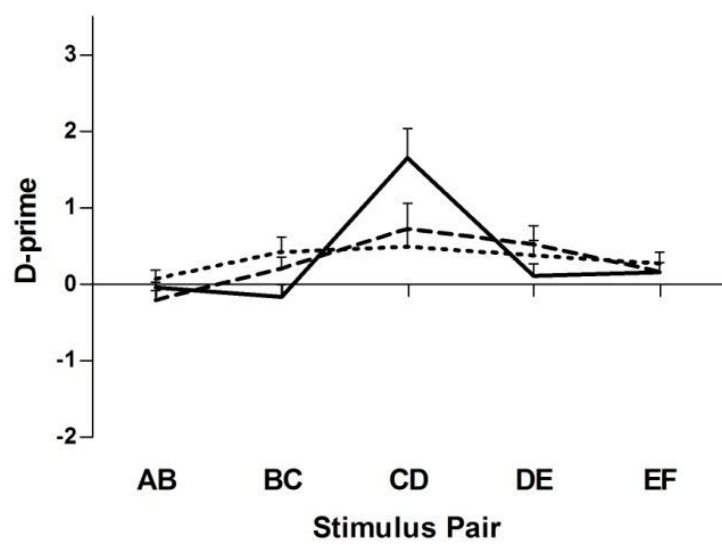

RA7

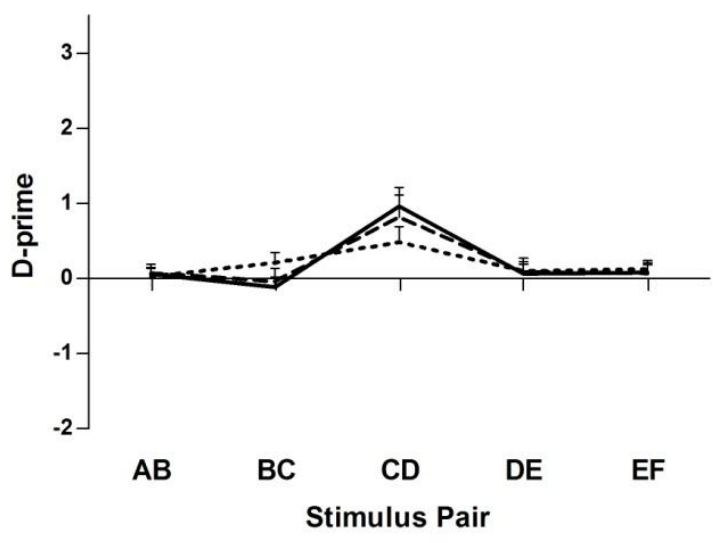

CA13

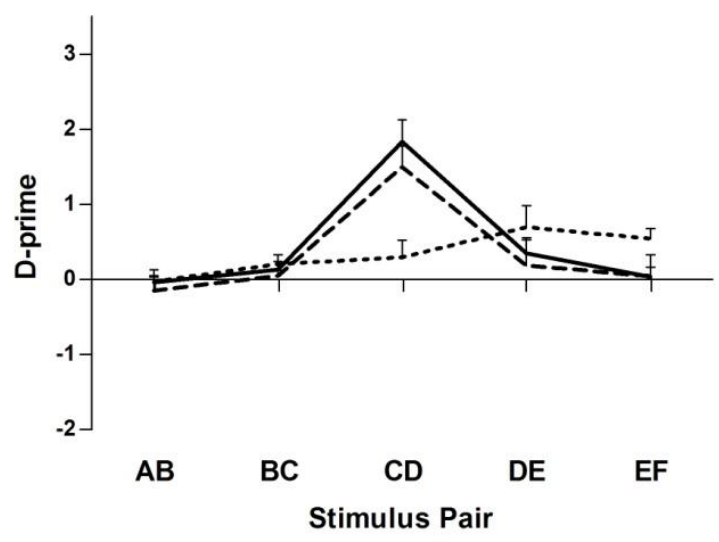

...... Non-speech

--- Speech

— Modulated speech 
Figure 4

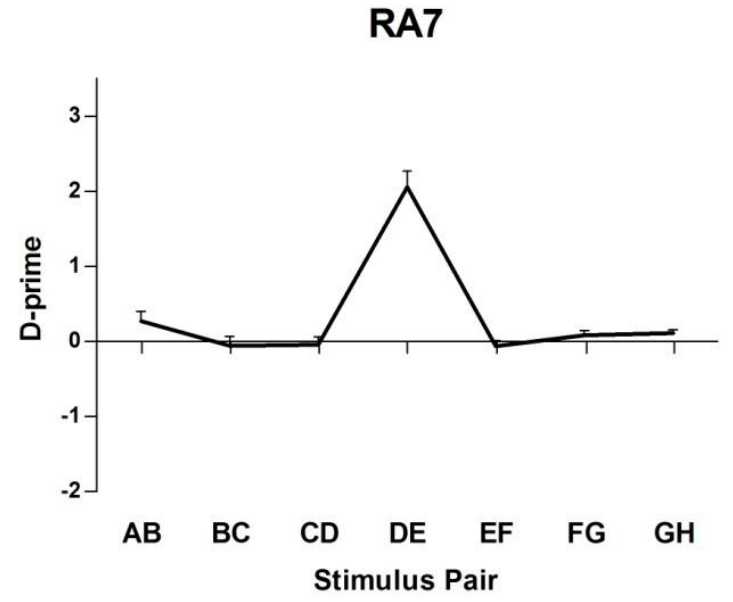

CA12

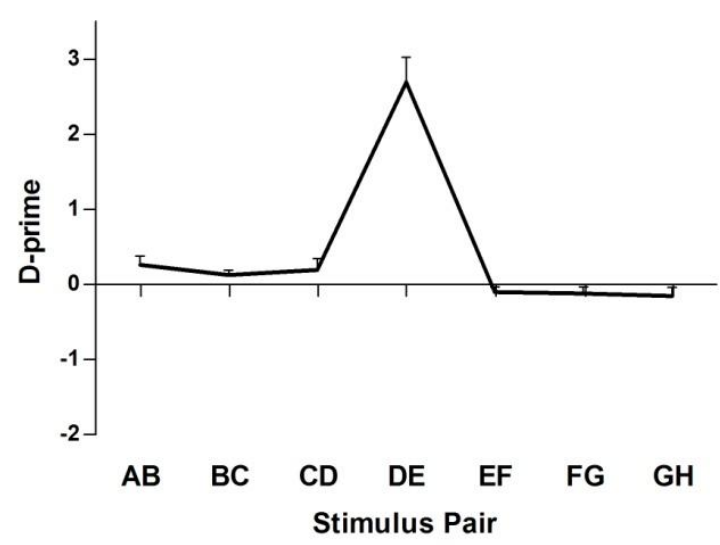

CAAD

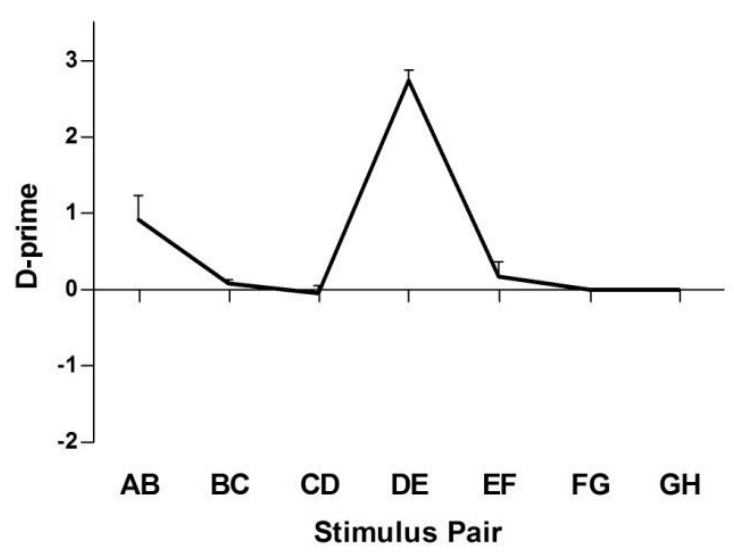

RA6

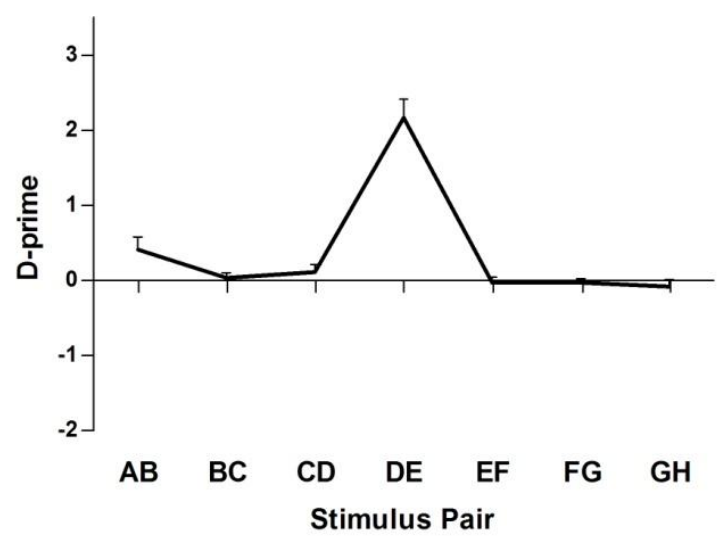

CA13

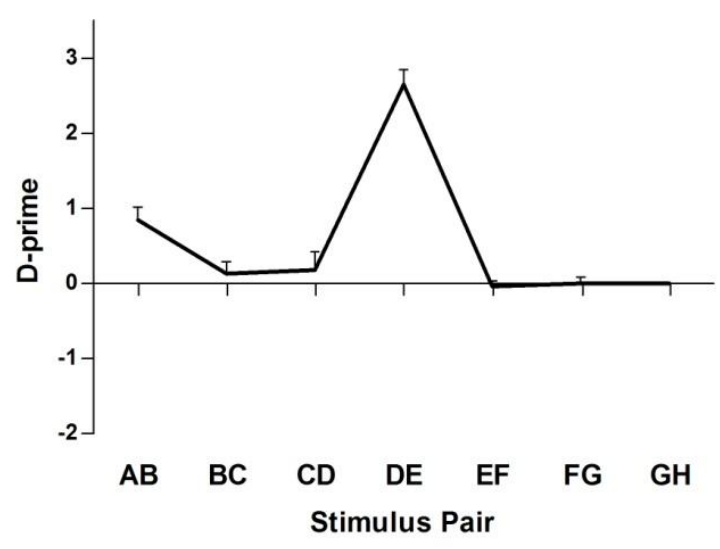

- d-t continuum 
Figure 5

\section{WS1}

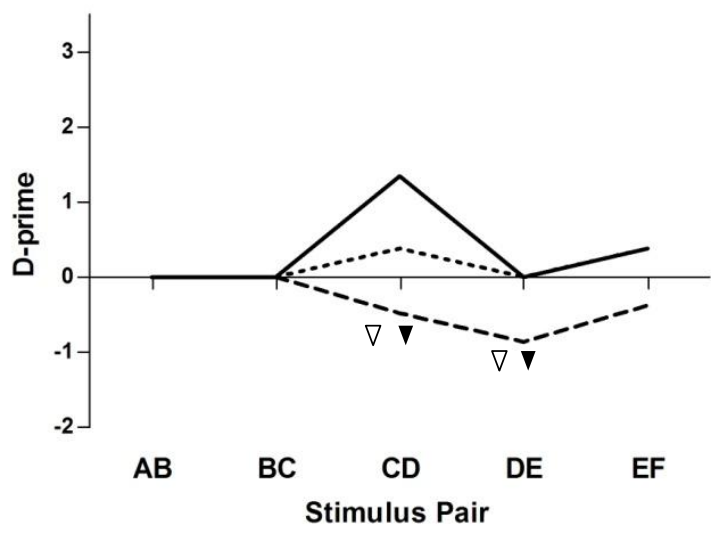

WS3

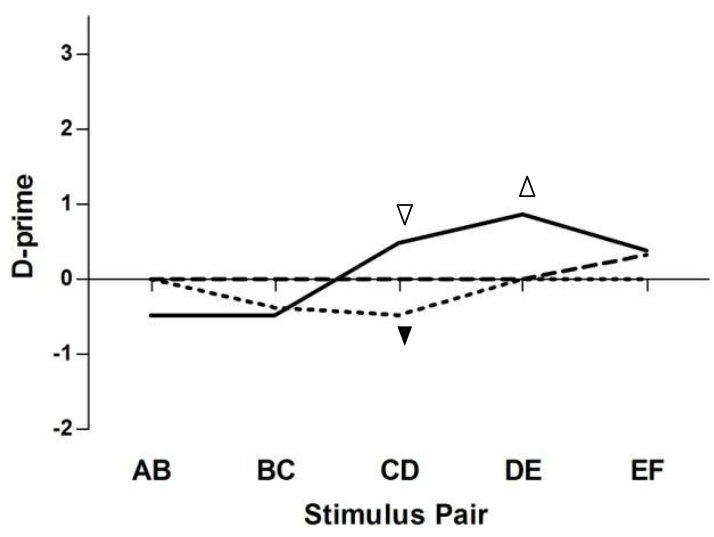

WS5

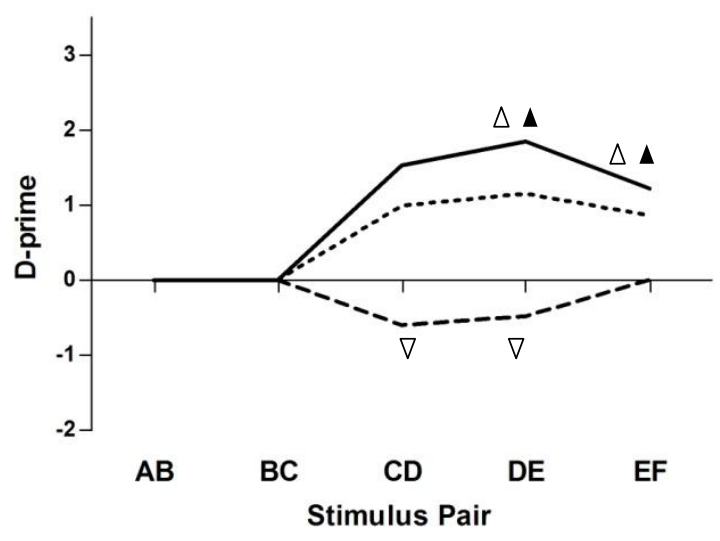

WS2

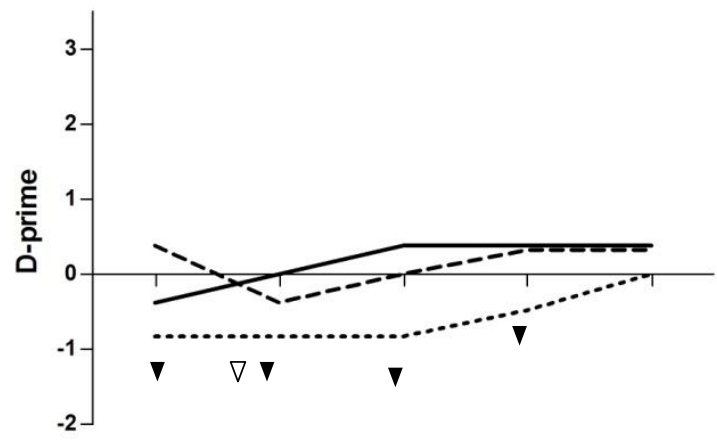

$\begin{array}{lll}A B & B C & C D \\ \text { Stimulus Pair } & D E & \text { EF }\end{array}$

WS4

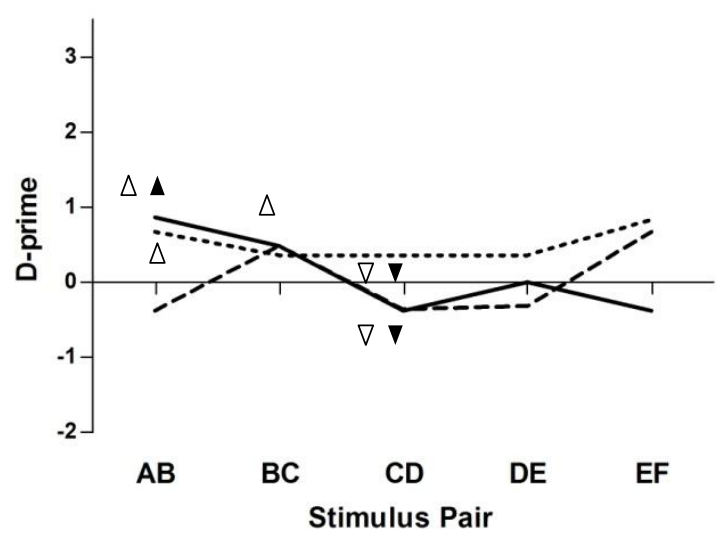

WS6

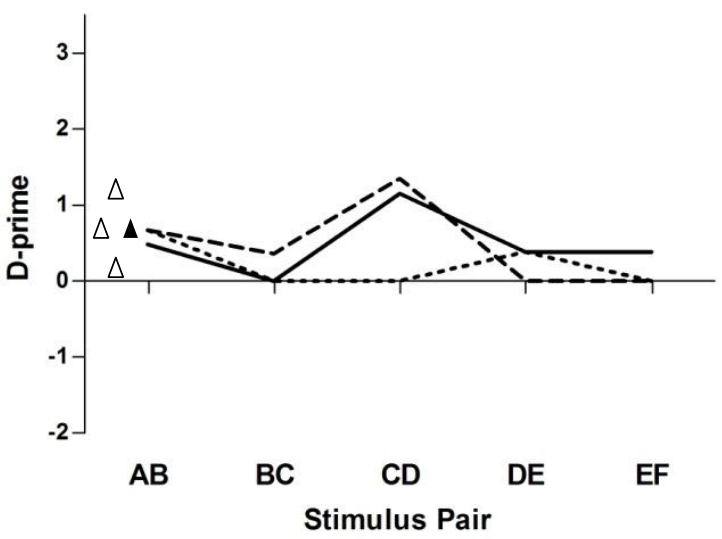

\footnotetext{
..... Non-speech

--- Speech

— Modulated speech
} 
Figure 6

WS1

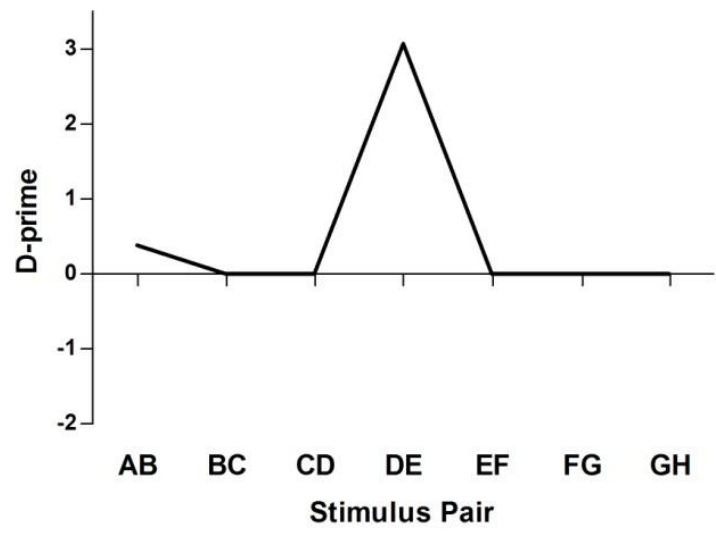

WS3

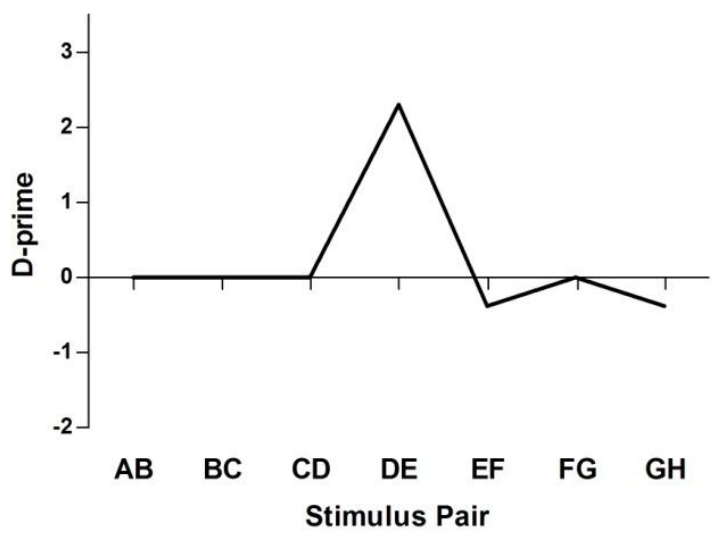

WS5

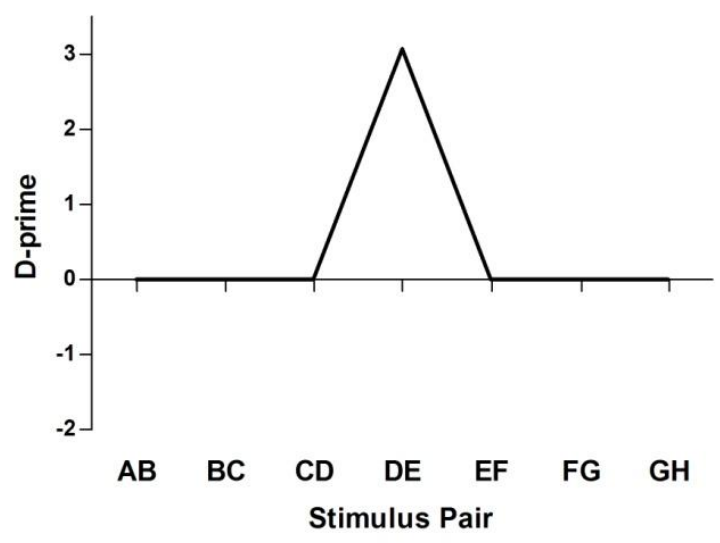

WS2

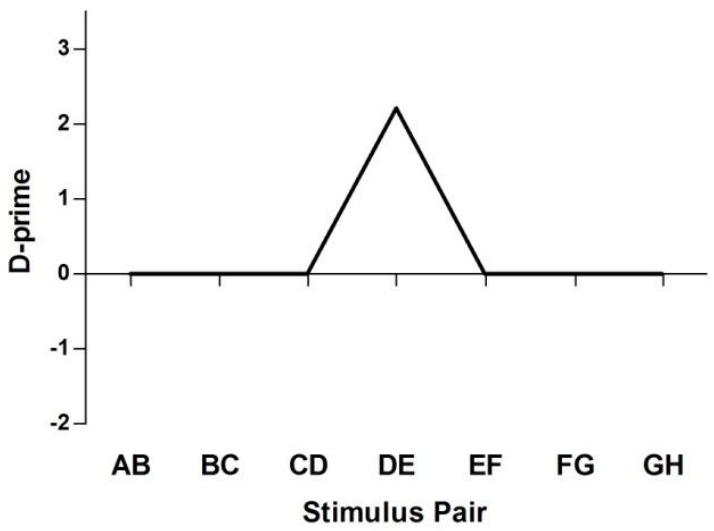

WS4

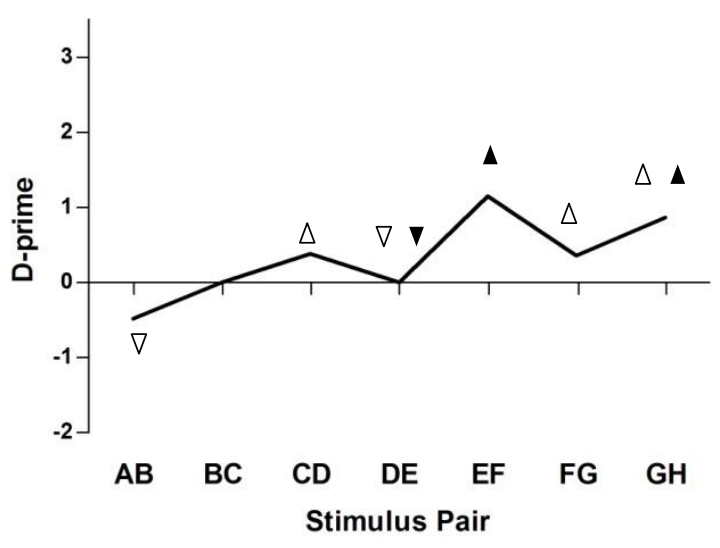

WS6

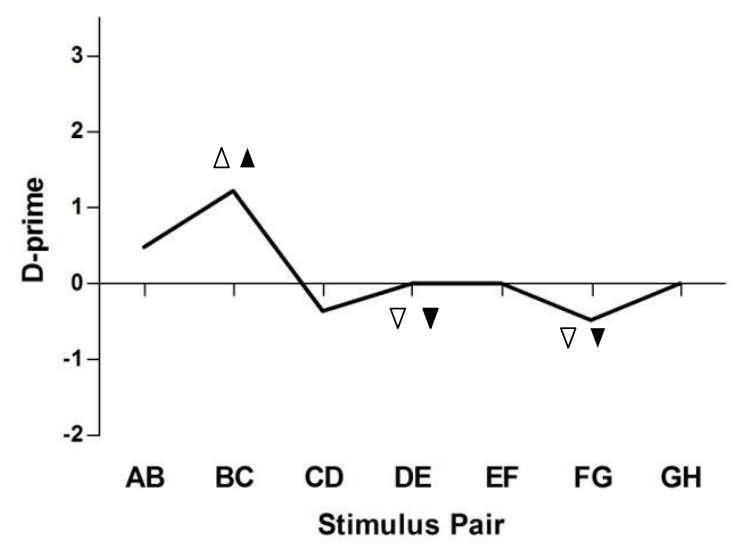

— d-t continuum 